\title{
CUESTIONES ACTUALES DE LA OCM ÚNICA EN MATERIA VITIVINÍCOLA
}

\author{
Fernando GONZÁLEZ BOTIJA \\ PROFESOR DE DERECHO ADMINISTRATIVO \\ UNIVERSIDAD COMPLUTENSE DE MADRID
}

\begin{abstract}
SUMARIO: I. Introducción. II. Régimen de autorización de plantaciones de vid. II.r. La vuelta al pasado: de nuevo el régimen de autorizaciones sin posibilidad de transferencia de derechos. II.2. Nuevo régimen de autorizaciones. II.3. Replantaciones. II.4. Sanciones. III. Protección de las denominaciones de origen y etiquetado.
\end{abstract}

RESUMEN: El presente trabajo examina la normativa sobre autorizaciones para plantación de viñedo contenida en el Reglamento (UE) $\mathrm{n}^{\circ}$ 1308/2013 y en el Reglamento Delegado de la Comisión $\mathrm{n}^{\circ}$ 2015/56I sobre la misma cuestión. Igualmente este trabajo recoge la reciente jurisprudencia del Tribunal Supremo español sobre la protección de denominaciones de origen.

Palabras Clave: Autorización. Viñedo. Plantación. Denominación de origen.

ABSTRACT: The current work examines the rules on a scheme of authorisations for vine plantings contained in Regulation (EU) $\mathrm{n}^{\circ} \mathrm{I} 308 / 20 \mathrm{I} 3$ and in Commission implementing Regulation (EU) $\mathrm{n}^{\circ}$ 2015/56I of 7 April 2015 laying down rules for the application of Regulation (EU) $\mathrm{n}^{\circ}$ I308/20I3 of the European Parliament and of the Council as regards the scheme of authorisations for vine plantings. This work also includes the recent case law of the Spanish Supreme Court on the protection of appellations of origin.

KEY WORDS: Authorisation. Vine plantings. Appellations of origin.

\section{Introducción}

El secretario general del Copa-Cogeca, Pekka Pesonen, ha declarado que el sector vitivinícola es un sector de excelencia en lo que se refiere al comercio de productos agroalimentarios entre la UE y los países extracomunitarios. Efectivamente, el sector vitivinícola sigue siendo un sector estratégico para nuestra economía agraria. Se ha dicho con razón que, bajo un punto de vista económico, la producción europea desempeña un papel estratégico y constituye, además, una importante fuente de empleo en muchas zonas rurales de la UE. España sigue beneficiándose enormemente de los fondos europeos de los cuales es el principal perceptor del dinero comunitario que se dedica al campo vitivinícola. Con todo hay que tener en cuenta que las ayudas directas a los viticultores (para el mosto y 
la destilación de uso de boca, así como para la destilación de crisis exclusivamente para uso industrial) no van a durar para siempre y es necesario seguir adaptando el sector a las necesidades del mercado.

La OCM sigue buscando la disciplina, como por ejemplo en cuanto a prácticas enológicas, intentado que se basen en las admitidas por la Organización Internacional de la Viña y el Vino $(\mathrm{OIV})^{\mathrm{I}}$ y en cuanto a etiquetado. Desde finales de la pasada década se han seguido potenciando las medidas de reestructuración, de modernización de la cadena productiva, de vendimia en verde, de gestión de crisis y los programas de arranque de viñedo ${ }^{2}$.

Vamos a centrarnos en este trabajo en el tema de los derechos de plantación y en la reciente jurisprudencia del Tribunal Supremo español sobre las denominaciones de origen.

\section{Régimen de autorización de plantaciones de vid ${ }^{3}$}

II.I. La vuelta al pasado: de nuevo el régimen de autorizaciones sin posibilidad de transferencia de derechos.

Desde hacía varios años se quería reformar la OCM del vino. Una de las mayores preocupaciones del sector giró en torno a su futuro tras la regulación de 2008 que vislumbraba un panorama de supresión de las transferencias los derechos de plantación y de liberalización de plantaciones a partir de 2015 o 20I8. El Reglamento (CE) n $n^{\circ}$ 479/2008 del Consejo se establecía que los derechos de plantación terminaban el 3I de diciembre de 20I5, si los Estrados miembros así lo decidían, o el 3I de diciembre de 20I84. Por otro lado la posibilidad de una liberalización de las plantaciones de viñedo hubiera supuesto una

'Sobre el mantenimiento de la práctica enológica de la chaptalización, véase YRAVEDRA, El fraude de la chaptalización en vinos de la Unión Europea, Madrid, AMV Ediciones, 2014.

${ }^{2}$ La UE sigue con su política de arranques, aunque la ambiciosa previsión fijada en 2007 con el tiempo hubo que replantearla a la baja. Expertos explican que esta disminución del número de hectáreas ha sido posible gracias a la presión de los países que consideraban que la solución no pasaba por disminuir el potencial de producción, sino por competir en el mercado con suficiente fuerza como para conseguir ganar mercado allí donde lo estaba perdiendo el vino de la UE. Lo cierto es que la política de primas al arranque ha seguido aunque con limitaciones, de tal modo que tanto las autoridades regionales, nacionales y comunitarias con el fin de evitar que se supere un excesivo porcentaje de superficie arrancada y priorizando los productores de más edad que decidan abandonar su explotación.

${ }^{3}$ Ver De Pablo Contreras (Dir.), El régimen jurídico de las plantaciones $y$ replantaciones de viñedo. (Derecho comunitario, estatal $y$ de la Comunidad Autónoma de La Rioja), Logroño, Ed. Gobierno y Universidad de La Rioja, 2002.

${ }^{4}$ Históricamente los derechos se han dirigido a personas físicas o jurídicas o comunidades de bienes que los utilizasen para realizar plantaciones que beneficiasen especialmente a jóvenes agricultores, agricultores a título principal y titulares de explotaciones prioritarias. Tradicionalmente se exigían los siguientes requisitos para poder acceder a los derechos: a) Cumplir la normativa vigente en materia de plantaciones de viñedo y en particular no ostentar la titularidad de parcelas ilegales. b) No haber sido beneficiario de primas por abandono definitivo del viñedo en la campaña de presentación de la solicitud o en las últimas cinco campañas vitivinícolas. c) No haber transferido derechos de replantación de viñedo en la campaña de presentación de la solicitud ni en las cinco campañas anteriores. d) No haber cedido o vendido derechos de replantación de viñedo para su incorporación a la Reserva Regional en la campaña de presentación de la solicitud ni en las cinco campañas anteriores. e) El solicitante no debía ser titular de derechos de replantación en el momento de la presentación de la solicitud. Los derechos se solían conceder de forma gratuita a los jóvenes agricultores que poseían capacitación profesional agraria suficiente y que se estableciesen por primera vez como jefe de explotación o cotitular de la misma, entendiéndose como tal el alta en el régimen especial de la seguridad social de los trabajadores por cuenta propia o autónomos o, en su caso, en el sistema especial de trabajadores por cuenta propia Agrarios. Al resto se les concedía a cambio de una contrapartida financiera. 
verdadera revolución para el sector. Estudios ${ }^{5}$ sobre si debían mantenerse o no los derechos de las plantaciones vitivinícolas en la UE revelaron graves impactos socioeconómicos y territoriales de llevarse a cabo su desaparición. Ante la Comisión Europea organizaciones agrarias, cooperativas, consejos reguladores de las denominaciones de origen y representantes de los Estados miembros ${ }^{6}$ manifestaron su preocupación por una posible liberalización. Pese a que es una realidad que las negociaciones internacionales en el seno de la OMC eran favorables a una desregulación, desde dentro de Europa se presionaba para preservar los fundamentos de una regulación que se seguí viendo como necesaria. De este modo se aportaban los siguientes argumentos para defender la continuación del marco regulatorio:

$\mathrm{I}^{\circ}$ ) los derechos de plantación no suponen una carga económica que impida competir con otros modelos productivos de los nuevos países productores, que el mercado libre no evita crisis de sobreproducción, 'Argentina y Australia, así lo han demostrado recientemente', que la supresión de tales derechos de producción sólo ha tenido lugar en aquellos territorios incapaces de cumplir las reglas de autorregulación y que el sistema de derechos de plantación ha permitido establecer estructuras socioeconómicas altamente competitivas, como lo demuestran las cifras de exportación de los vinos españoles y europeos.

$2^{\circ}$ ) el sistema de derechos de plantación no fomentó un sector rígido, sino que permitió reasignaciones en las regiones en las que los mercados mostraban crecimiento (Francia, Italia, Alentejo).

$3^{\circ}$ ) la desaparición de los derechos de plantación podía promover nuevas plantaciones en nuevas localizaciones que podrían competir con zonas de cultivo con vocación vitícola (zonas geográficas delimitadas todavía sin plantar) o zonas de cultivo con vocación general o también zonas por desbrozar.

$\left.4^{\circ}\right)$ su eliminación conllevaría nefastas consecuencias económicas, sociales, medioambientales, territoriales y paisajísticas que el cambio de modelo traería como consecuencia de una desregulación basada en productividades y volúmenes de producción no ligados a la calidad. Se iniciará una deslocalización hacia las llanuras y se afectará al enoturismo y su economía naciente (con consecuencias negativas para el empleo) así como la competitividad de los viñedos de montaña y de pendiente fuerte, con todas las consecuencias medioambientales inducidas.

$5^{\circ}$ ) el sistema de derechos de plantación sirvió de ayuda para acompañar al mercado y la producción vinícolas de la Unión, mediante un aumento regular de las superficies de viñedo, a la vez que garantizó la calidad del vino producido en la UE.

$6^{\circ}$ ) la supresión de los derechos agravaría los desequilibrios existentes de la cadena alimentaria, en detrimento del sector productor.

\footnotetext{
${ }^{5}$ Ver, por ejemplo, Estudio sobre los impactos socioeconómicos y territoriales de la liberalización de los derechos de plantaciones vitícolas, presentado por la Asociación de Regiones Europeas Vitícolas (AREV). Este estudio analizó si los derechos de plantación del sector vitivinícola de la UE deberían mantenerse o no y se debatió ante el Parlamento europeo. Véase también el estudio elaborado por el Istituto Nazionale di Economia Agraria (INEA), que fue encargado por la Eurocámara, titulado: «La liberalización de los derechos de plantación del sector vitivinícola de la UE».

${ }^{6}$ Se opusieron a la supresión en 20I5: Francia, Alemania, Italia, Chipre, Luxemburgo, Austria, Hungría, Portugal, Rumanía, República Checa, Grecia, España, Eslovaquia, Eslovenia y Bulgaria.
} 
Por ello se defendió con vehemencia que el mantenimiento de los derechos de plantación, en lugar de suprimirlos paulatinamente, lo que causó gran preocupación en el sector vitivinícola de la UE. Su continuación se veía como una manera de que los productores pudiesen proceder a las inversiones necesarias. Los eurodiputados pidieron ya el mantenimiento de estos derechos después de 2015, en lugar de su supresión progresiva, con motivo de la votación del informe sobre el futuro de la PAC en mayo.

Al final el legislador comunitario optó por un cambio en su estrategia. Se ha destacado que después de una intensa batalla diplomática y de alianzas, el Parlamento Europeo (por primera vez codecisorio en temas agrarios) y los países productores han conseguido dar la vuelta a la OCM. Así, se adoptó un régimen de autorizaciones administrativas que supone una vuelta a los orígenes de la regulación aprobada en la década de los setenta. Así, el Reglamento (UE) $\mathrm{n}^{\circ} \mathrm{I} 308 / 2013^{7}$ incluye, en la parte II, título I, capítulo III, normas relativas a un régimen de autorizaciones para plantaciones de vid que deroga y sustituye, a partir del i de enero de 2016 , el régimen transitorio de derechos de plantación establecido en la parte II, título I, capítulo III, sección IV bis, subsección II, del Reglamento (CE) $n^{\circ}$ I234/2007 del Consejo ${ }^{8}$. Ese capítulo establece normas sobre la duración, la gestión y el control del régimen de autorizaciones para plantaciones de vid, y faculta a la Comisión para adoptar actos delegados en lo referente a la gestión del régimen. El régimen transitorio de derechos de plantación establecido en la parte II, título I, capítulo III, sección IV bis, subsección II, del Reglamento (CE) n I234/20079 sigue siendo aplicable hasta el 3I de diciembre de 2015, de conformidad con el artículo 230, apartado I, letra b), inciso ii), del Reglamento (UE) $n^{\circ} \mathrm{I308/2013}$. El nuevo régimen se ha desarrollado en el Reglamento Delegado (UE) 2015/560 de la Comisión de I5 de diciembre de 2014 por el que se completa el Reglamento (UE) n ${ }^{\circ}$ 1308/2013 del Parlamento Europeo y del Consejo en lo que respecta al régimen de autorizaciones para plantaciones de vid ${ }^{\mathrm{I}}$.

De este modo el artículo 6r del Reglamento I308/20I3, dispone en cuanto a la vigencia, que el régimen de autorizaciones para plantaciones de vid establecido en el presente capítulo se aplicará entre el I de enero de 2016 y el 3I de diciembre de 2030 con una revisión intermedia que deberá realizar la Comisión para evaluar el funcionamiento del régimen $\mathrm{y}$, en caso pertinente, formular propuestas ${ }^{\mathrm{II}}$.

\footnotetext{
${ }^{7}$ Ver Reglamento (UE) n ${ }^{\circ}$ 1308/20I3 del Parlamento Europeo y del Consejo, de I7 de diciembre de 20I3, por el que se crea la organización común de mercados de los productos agrarios y por el que se derogan los Reglamentos (CEE) n 922/72, (CEE) n 234/79, (CE) n I037/2001 y (CE) n 1234/2007 del Consejo, DO L 347 de 20.12.2013, p. 67I.

${ }^{8}$ Ver DO L 347 de 20.12.2013, p. 549.

${ }^{9}$ Ver Reglamento (CE) $n^{\circ}$ I234/2007 del Consejo, de 22 de octubre de 2007 , por el que se crea una organización común de mercados agrícolas y se establecen disposiciones específicas para determinados productos agrícolas (Reglamento único para las OCM), DO L 299 de I6.II.2007, p. I.

${ }^{10}$ Ver DO L 93 de 9.4.20I5, p.I. Véase también el Reglamento de Ejecución (UE) 2015/56I de la Comisión de 7 de abril de 2015 por el que se establecen disposiciones de aplicación del Reglamento (UE) n ${ }^{\circ}$ I308/20I3 del Parlamento Europeo y del Consejo en lo que respecta al régimen de autorizaciones para plantaciones de vid, DO L 93 de 9.4.20I5, p.I2.

${ }^{\text {II }}$ Se ha aclarado que este era otro tema pendiente de cerrar. «El nuevo sistema de autorizaciones entraría en vigor en el año 20I9 y el Parlamento Europeo propuso estirarlo hasta el 2030. No obstante, la Presidencia irlandesa del Consejo planteó el 2024 como fecha límite, si bien eran dieciséis los países que querían llegar hasta el año 2030. Desde La Rioja se dice que tenía sentido una posición intermedia (2028), aunque también dejó claro que el Parlamento Europeo podía ceder en este tema, pero no en el porcentaje de aumento de plantaciones anual más allá del o,5\% o, como mucho, del I\%..
} 
Por tanto, el viejo régimen finaliza el 3I de diciembre de 20I5. A partir de entonces sólo se podrá plantar viñedo con autorizaciones administrativas. Este nuevo sistema, según la Administración permite continuar con una limitación de la producción y asegurar un crecimiento ordenado de las plantaciones de $\mathrm{vid}^{\mathrm{I}}$. El propio legislador prevé un régimen transitorio en el artículo 68 del Reglamento (UE) no I308/20I3 al disponer lo siguiente:

«I. Los derechos de plantación concedidos a productores de conformidad con los artículos 85 nonies, 85 decies o 85 duodecies del Reglamento (CE) n o I234/2007 antes del 3I de diciembre de 20I5, que no hayan sido utilizados por dichos productores y sean todavía válidos a esa fecha, podrán convertirse en autorizaciones con arreglo al presente capítulo a partir del I de enero de 20I6. Dicha conversión tendrá lugar previa petición presentada por esos productores antes del 3I de diciembre de 20I5. Los Estados miembros podrán decidir permitir que los productores presenten la solicitud para convertir los derechos en autorizaciones hasta el 3I de diciembre de 2020.

2. Las autorizaciones concedidas con arreglo al apartado I tendrán el mismo periodo de validez que los derechos de plantación contemplados en el apartado I. Si no se utilizan dichas autorizaciones, expirarán a más tardar el 31 de diciembre de 20I8, o a más tardar el 3I de diciembre de 2023 si los Estados miembros han adoptado la decisión contemplada en el apartado I, párrafo segundo.

3. Las superficies cubiertas por las autorizaciones concedidas con arreglo al apartado I no serán contadas a efectos del artículo 63».

De este modo se pone punto final a las transferencias de derechos entre comunidades autónomas y provincias [por ejemplo, entre distintas denominaciones de origen de una misma región], y a los intercambios entre particulares. Los derechos de plantación acabarán perdiendo su valor en un período transitorio. Por eso se ha advertido que «la principal diferencia de ambos sistemas es que ni los derechos antiguos ni las autorizaciones nuevas podrán venderse entre particulares, con lo que desaparecerá el patrimonio del 'papel' a partir del 20I9. Lo que hace el sistema es acabar con la 'especulación'. Es decir, lo que valdrá es la tierra y no el 'papel'. Las nuevas autorizaciones serán gratuitas, pero, si no se utilizan en tres años, caducarán y volverán a la administración». Con el fin de avanzar en el proceso de transición de los actuales derechos de plantación al de permisos administrativos, que será operativo a partir del i de enero de 20I6, el Ministerio trabaja con las comunidades autónomas en una nueva normativa para adaptarse a la nueva situación ${ }^{\mathrm{I}}$. Las Consejerías de agricultura de las CCAA tratan con las organizaciones agrarias y representantes del sector vitivinícola con el fin de facilitar la transición para los viticultores.

\footnotetext{
${ }^{12}$ Ver «Nuevas 'autorizaciones', cambio cosmético derechos de plantación: nuevo nombre», en www.elmundo vino.com.

${ }^{13}$ Sobre la normativa española véase http://www.magrama.gob.es/es/agricultura/temas/regulacion-de-losmercados/organizaciones-comunes-de-mercado-y-regimenes-de-ayuda/ocm-vitivinicola/. Ver Real Decreto I244/2008, de I 8 de julio, por el que se regula el potencial de producción vitícola. Es de especial interés consultar SÁNCHEZ HERNÁNDEZ, «Aproximación al régimen jurídico vitivinícola español: algunos aspectos significativos de la Ley 24/2003, de Io de julio, de la Viña y del Vino», Cuadernos de derecho agrario, nº ${ }^{\circ}$, 2005 (Ejemplar dedicado a: Las nuevas orientaciones normativas de la PAC y de la legislación agraria nacional, coord. por Ángel SÁnchez HernándeZ y Pedro Valentín DE PABlo ContrerAS), págs.303-332.
} 
Los viticultores que tengan derechos sin plantar en propiedad deberán solicitar su conversión en autorizaciones teniendo un margen desde el I de septiembre del 2015 hasta el 3I de diciembre del 2020, aunque deberán ser conscientes de la fecha de caducidad de los mismos. Se ha previsto regular esta cuestión de la conversión de derechos de plantación de viñedo en autorizaciones de forma urgente, y con antelación al Real Decreto general que va a regular el sistema de autorizaciones, con el objeto de que el sector conozca cuanto antes, y con suficiente antelación, tanto el procedimiento como los plazos para poder planificarse. La ventanilla para solicitar las conversiones se abre el i5 de septiembre de 2015 conforme a la normativa comunitaria y, dado que el reglamento permite al Estado miembro posponer la fecha de finalización de solicitud de conversiones, desde el 3I de diciembre de 2015 al 3I de diciembre de 2020, el Ministerio ha propuesto que sea el 3I de diciembre de 2020. Es el plazo máximo para convertir los derechos en permisos. Si no se cambian para esa fecha, desaparecerán.

Los derechos de plantación actuales caducan a los ocho años de no utilizarlos desde que se generan, mientras que las nuevas autorizaciones lo hacen a los tres, por lo que es posible que interese aplazar el cambio para agotar al máximo la vigencia. De ahí que se deje un margen tan amplio de cinco años para su conversión con el fin de no perjudicar a los viticultores. Se ha dicho que el objetivo es permitir la planificación empresarial para los viticultores con derechos en cartera, y evitar la concentración de plantaciones en los tres primeros años de aplicación del régimen de autorizaciones.

El viticultor que no quiere reconvertirse tiene la opción de vender sus derechos en el mercado antes de que se acabe el plazo, siendo previsible que el comercio entre viticultores y bodegas con los derechos de plantación de viñedos se extienda previsiblemente algo más de tiempo. La idea ha sido modificar la normativa sobre tramitación de transferencias y cesiones de derechos, cuya autorización corresponde al Ministerio, ampliándose la fecha límite de presentación de solicitudes para este tipo de transferencias en la última campaña, antes de la desaparición de los derechos. Los conocedores del mercado de derechos de plantación explican que en la actualidad existe una demanda, especialmente de jóvenes, claramente superior a la oferta, pero la realidad es que no hay oferta», De hecho, la presunción de prácticamente todo el sector es que los derechos incrementarán su precio a medida que se acerque la fecha final para su comercio. Se destaca que no existe tendencia a vender porque al ser rentable el viñedo se ve como un bien seguro que da trabajo e ingresos, frente a una situación económica incierta y unas opciones de rentabilidad con el dinero menos atractivas dados los intereses que paga la banca o la deuda pública ${ }^{\text {I4 }}$. También se tiene en cuenta la existencia del período transitorio.

\section{II.2. Nuevo régimen de autorizaciones}

Con el nuevo régimen el viticultor que desee plantar deberá someterse a un clásico control autorizatorio que garantizará el control del potencial vitícola. Es decir, se establece

\footnotetext{
${ }^{14}$ En La Rioja se estima que la cotización actual de los derechos ronda entre los 15.000 a 18.000 euros por hectárea (hace diez años llegaron a valer 30.000 euros), aunque se espera un incremento de precio antes del paso al sistema de autorizaciones, el valor en el mercado del «papel» que hay en la denominación Rioja sería de unos I.I34 millones de euros (62.000 hectáreas de viñedo de Rioja que está en manos de unos I8.000 viticultores) y de entre 645 y 774 millones (unas 43.000 hectáreas) en La Rioja. El valor de mercado desaparecerá a partir de la fecha que se fije para la prohibición del comercio.
} 
así un régimen de autorizaciones para plantaciones de vid. Se ha explicado que el gran éxito de las negociaciones del Parlamento Europea ha sido la garantía de un sistema de control de la masa vegetal. La gran diferencia es que las autorizaciones, a diferencia de los derechos, no serán transferibles y no tendrán valor económico como hasta ahora. De este modo el artículo 62 del Reglamento (UE) n ${ }^{\circ}$ I308/2013 establece la obligación general de los Estados miembros de conceder una autorización para la plantación de vid previa presentación de una solicitud por parte de los productores que tengan intención de plantar o replantar vides. Así, dispone lo siguiente:

«I. Las vides de las variedades de uva de vinificación clasificadas de acuerdo con el artículo 8I, apartado 2, podrán ser plantadas o replantadas únicamente si se concede una autorización de conformidad con los artículos 64, 66 y 68 con arreglo a las condiciones establecidas en el presente capítulo.

2. Los Estados miembros concederán la autorización contemplada en el apartado I, correspondiente a una superficie específica expresada en hectáreas, previa presentación por parte de los productores de una solicitud que cumpla con los criterios de admisibilidad objetivos y no discriminatorios. Dicha autorización será concedida sin coste para los productores.

3. Las autorizaciones a que se refiere el apartado i serán válidas por un periodo de tres años a partir de la fecha en que hayan sido concedidas. Los productores que no hayan utilizado la autorización que se les haya concedido durante el periodo de validez serán objeto de las sanciones administrativas previstas en el artículo 89, apartado 4, del Reglamento (UE) n o I306/2013.

4. El presente capítulo no se aplicará a la plantación o replantación de superficies destinadas a fines experimentales o al cultivo de viñas madres de injertos, a las superficies cuyo vino o productos vitivinícolas estén destinados exclusivamente al autoconsumo del viticultor o a las superficies para nuevas plantaciones resultantes de expropiaciones por causa de utilidad pública llevadas a cabo al amparo de la legislación nacional».

El Reglamento Delegado (UE) 2015/560 ha desarrollado este apartado 4 que prevé que determinadas superficies estén exentas del régimen de autorizaciones de plantaciones de vid y, por tanto, de esta obligación general. Ha sido necesario establecer normas relativas a las condiciones de aplicación de dicha exención ${ }^{15}$. Las superficies destinadas a fines

\footnotetext{
${ }^{15}$ El artículo I (Superficies exentas del régimen de autorizaciones para plantaciones de vid) dispone lo siguiente: I. El régimen de autorizaciones para plantaciones de vid establecido en la parte II, título I, capítulo III, del Reglamento (UE) n I308/2013 no se aplicará a la plantación o replantación de las superficies a que se refiere el artículo 62, apartado 4, de dicho Reglamento que cumplan las condiciones pertinentes establecidas en los apartados 2,3 y 4 del presente artículo. 2. La plantación o replantación de superficies destinadas a fines experimentales o al cultivo de viñas madres de injertos se notificará previamente a las autoridades competentes. La notificación incluirá toda la información pertinente sobre esas superficies y el período durante el cual tendrá lugar el experimento o el período de producción de viñas madres de injertos. También se notificará a las autoridades competentes la ampliación de tales períodos. Cuando se considere que no hay riesgo de perturbación del mercado, los Estados miembros podrán decidir autorizar la comercialización de la uva producida en esas superficies y de los productos vitícolas obtenidos a partir de dicha uva durante los períodos contemplados en el párrafo primero. Al término de dichos períodos, el productor deberá: a) obtener una autorización de conformidad con los artículos 64 o 68 del Reglamento (UE) n ${ }^{\circ}$ I308/2013 para la superficie de que se trate, de manera que puedan comercializarse la uva producida en esa superficie y los productos vitícolas obtenidos a partir de esa uva, o b) arrancar esa superficie, asumiendo el coste, de conformidad con el artículo 7I, apartado I, del Reglamento (UE) n 1308/2013. Las superficies destinadas a la experimentación o al cultivo de viñas madres de injertos plantadas antes del I de enero de 2016 tras la concesión de derechos de nueva plantación seguirán cumpliendo después de esa fecha todas las condiciones definidas para la utilización
} 
experimentales o al cultivo de viñas madres de injertos deben utilizarse únicamente para los fines especificados a fin de evitar la elusión del nuevo régimen, y los productos vitícolas obtenidos de esas superficies no deben comercializarse a menos que los Estados miembros consideren que no existe riesgo de perturbación del mercado. Se entiende que deben seguir permitiéndose los experimentos vitícolas y los cultivos de viñas madres de injertos ya existentes, sujetos a las normas existentes para garantizar la correcta transición entre el régimen de derechos de plantación y el nuevo régimen de autorizaciones para plantaciones de vid. Las superficies cuyo vino o cuyos productos vitícolas estén destinados exclusivamente al autoconsumo del viticultor deben beneficiarse de esa exención, ya que, en determinadas condiciones, no contribuyen a las perturbaciones del mercado. Por la misma razón, ha convenido ampliar asimismo esa exención a las organizaciones sin una actividad comercial que cumplan las mismas condiciones. Las superficies establecidas por un productor que haya perdido una determinada superficie plantada con vid debido a la expropiación por causa de utilidad pública al amparo de la legislación nacional deben beneficiarse también de la exención, dado que la pérdida de tierras plantadas con vid es en tales casos independiente de la voluntad del productor. Sin embargo, ha convenido establecer una condición en cuanto a la superficie máxima de la nueva superficie a fin de evitar socavar los objetivos generales del régimen de autorizaciones para plantaciones de vid.

En el artículo 63 del Reglamento (UE) no $n^{\circ} 308 / 2013$ se regula el mecanismo de salvaguardia para nuevas plantaciones conforme al siguiente régimen:

«I. Los Estados miembros pondrán a disposición, cada año, autorizaciones para nuevas plantaciones correspondientes al i \% de toda la superficie realmente plantada con vid en su territorio, calculada el 3I de julio del año anterior.

2. Los Estados miembros podrán:

a) aplicar, a nivel nacional, un porcentaje menor al establecido en el apartado I;

b) limitar la expedición de autorizaciones a nivel regional, para superficies específicas que puedan optar a la producción de vinos con denominación de origen protegida, para superficies que puedan optar a la producción de vinos con indicación geográfica protegida o para superficies sin indicación geográfica.

de tales derechos hasta el final del período experimental o de producción de viñas madres de injertos para el que hayan sido concedidos. Una vez expirados dichos períodos, se aplicarán las normas establecidas en los párrafos primero y segundo. 3. La plantación o replantación de superficies cuyo vino o cuyos productos vitícolas estén destinados exclusivamente al autoconsumo de la familia del viticultor estará sujeta a las siguientes condiciones: a) esa superficie no excede de o,I ha; b) el viticultor de que se trate no se dedica a la producción de vino o de otros productos vitícolas con fines comerciales. A efectos del presente apartado, los Estados miembros pueden considerar equivalentes a la familia del viticultor determinadas organizaciones sin una actividad comercial. Los Estados miembros podrán decidir que las plantaciones contempladas en el párrafo primero estén sujetas a notificación. 4. Un productor que haya perdido una determinada superficie plantada con vid como resultado de expropiaciones por causa de utilidad pública al amparo de la legislación nacional tendrá derecho a plantar una nueva superficie, siempre que esa superficie plantada no exceda del 105\% de la superficie perdida en términos de cultivo puro. La superficie nuevamente plantada se inscribirá en el registro vitícola. 5. El arranque de las superficies que se beneficien de la exención a que se refieren los apartados 2 y 3 no dará dar lugar a una autorización de replantación con arreglo a lo dispuesto en el artículo 66 del Reglamento (UE) n I308/20I3. No obstante, dicha autorización se concederá en caso de arranque de superficies objeto de nuevas plantaciones al amparo de la exención a que se refiere el apartado 4 . 
3. Cualquiera de las limitaciones a que se refieren el apartado 2 deberá contribuir a una expansión ordenada de las plantaciones de vid, dar lugar a un crecimiento por encima del o \% y justificarse con uno o varios de los siguientes motivos específicos:

a) la necesidad de evitar el riesgo claramente demostrado de oferta excesiva de productos vinícolas en relación con las perspectivas de mercado para esos productos, sin exceder lo que sea necesario para satisfacer dicha necesidad;

b) la necesidad de evitar un riesgo bien demostrado de devaluación significativa de una denominación de origen protegida o indicación geográfica protegida concretas.

4. Los Estados miembros deberán hacer pública cualquier decisión adoptada con arreglo al apartado 2, que deberá ser debidamente justificada. Los Estados miembros deberán notificar inmediatamente a la Comisión esas decisiones y justificaciones».

En relación con el porcentaje previsto en el apartado I se ha dicho que de este modo se ha parado la liberalización encubierta que supondría un aumento automático del $2 \%$ de la masa vegetal año a año como en segunda instancia proponía la Comisión Europea. Frente a esta postura de la Comisión Europea, el Parlamento quiso que no fuese más del 0,5\%, mientras los países tenían sobre la mesa el I\%, porcentaje que, como puede verse, al final se impuso. Ahora bien, como puede verse se puede modular en el nivel nacional o regional un crecimiento menor, en línea con la postura que defendía el Parlamento, añadiéndose un plus a la regulación y control del potencial vitícola. Se supone que se primará a jóvenes y propietarios de tierra, entre otros, si se considera aumentar la masa vegetal.

El artículo 64 del Reglamento (UE) $\mathrm{n}^{\circ}$ 1308/2013 regula la concesión de autorizaciones para nuevas plantaciones del siguiente modo:

«I. Si la superficie total cubierta por las solicitudes admisibles, en un año determinado, no excede la superficie puesta a disposición por el Estado miembro, se aceptarán todas esas solicitudes. A los efectos del presente artículo, los Estados miembros podrán aplicar uno o varios de los siguientes criterios objetivos y no discriminatorios de admisibilidad:

a) el solicitante dispondrá de una superficie agrícola no menor que la superficie para la que solicita la autorización;

b) el solicitante tendrá la capacidad y competencia profesionales adecuadas;

c) la solicitud no supondrá un riesgo significativo de apropiación indebida de reputación de denominaciones de origen protegidas específicas, lo que se presumirá a menos que la existencia de tal riesgo quede demostrada por los poderes públicos;

d) cuando esté debidamente justificado, se aplicarán uno o varios de los criterios mencionados en el apartado 2, siempre que se haga de manera objetiva y no discriminatoria.

2. Si, en un año concreto, la superficie total cubierta por las solicitudes admisibles contempladas en el apartado I supera a la superficie puesta a disposición por los Estados miembros, las autorizaciones se concederán de acuerdo a una distribución proporcional de hectáreas a todos los solicitantes sobre la base de la superficie para la que hayan solicitado la 
autorización. También podrá procederse a dicha concesión parcial o totalmente de acuerdo con uno o varios de los siguientes criterios de prioridad objetivos y no discriminatorios:

a) que los productores planten vides por primera vez y estén establecidos en calidad de jefes de la explotación (nuevos viticultores);

b) que se trate de superficies donde los viñedos contribuyan a la preservación del medio ambiente;

c) que se trate de superficies para replantación en el marco de proyectos de concentración parcelaria;

d) que se trate de superficies con limitaciones específicas naturales o de otro tipo;

e) la sostenibilidad de los proyectos de desarrollo sobre la base de una evaluación económica;

f) que se trate de superficies para replantación que contribuyan a aumentar la competitividad en una explotación agrícola ya escala regional;

g) el potencial para mejorar la calidad de los productos con indicaciones geográficas;

h) que se trate de superficies para replantación en el marco del incremento del tamaño de las pequeñas y medianas explotaciones.

3. Los Estados miembros harán públicos los criterios de prioridad contemplados en los apartados I y 2 que apliquen y los notificarán inmediatamente a la Comisión».

Como acabamos de ver el artículo 64, apartados i y 2, del Reglamento (UE) $\mathrm{n}^{\circ} \mathrm{I308/2013}$ prevé normas relativas a la concesión de autorizaciones para nuevas plantaciones y establece los criterios de admisibilidad y de prioridad que pueden aplicar los Estados miembros. El Reglamento Delegado (UE) 2015/560 ha establecido condiciones específicas asociadas a algunos de los criterios de admisibilidad y de prioridad a fin de determinar condiciones equitativas para su aplicación y evitar la elusión del régimen de autorizaciones por parte de los productores a quienes se concedan. Además, se han añadido tres nuevos criterios: un nuevo criterio de admisibilidad relativo a la apropiación indebida de la reputación de indicaciones geográficas protegidas; un nuevo criterio de prioridad a favor de los productores que cumplan las normas del régimen y no hayan abandonado los viñedos de su explotación; y un nuevo criterio de prioridad a favor de las organizaciones sin ánimo de lucro con finalidad social que hayan recibido tierras decomisadas en caso de terrorismo y delitos de otro tipo. El nuevo criterio de admisibilidad responde a la necesidad de proteger la reputación de indicaciones geográficas específicas de la misma manera que la reputación de denominaciones de origen específicas, garantizando que no se vean amenazadas por las nuevas plantaciones. El primer nuevo criterio de prioridad favorece a determinados solicitantes sobre la base de antecedentes que demuestren su respeto de las normas del régimen de autorizaciones y que no solicitan autorizaciones para nuevas plantaciones aun teniendo superficies plantadas con vides retiradas de la producción que podrían dar lugar a autorizaciones de replantación. El segundo nuevo criterio de prioridad tiene por objeto favorecer a las organizaciones sin ánimo de lucro con finalidad social que hayan recibido tierras decomisadas en caso de terrorismo y delitos de otro tipo, a fin de promover la utilización social de tierras que, de lo contrario, correrían el riesgo de ser retiradas de la producción. 
De este modo el artículo 2 del Reglamento Delegado (UE) 2015/560 introduce los siguientes criterios para la concesión de autorizaciones:

«I. Cuando los Estados miembros apliquen el criterio de admisibilidad contemplado en el artículo 64, apartado I, letra c), del Reglamento (UE) $\mathrm{n}^{\circ} \mathrm{1308} / 2013$, se aplicarán las normas establecidas en el anexo I, parte A, del presente Reglamento ${ }^{16}$. Los Estados miembros podrán aplicar asimismo el criterio objetivo y no discriminatorio suplementario según el cual la solicitud no supondrá un riesgo significativo de apropiación indebida de la reputación de indicaciones geográficas protegidas específicas, lo que se presumirá a menos que la existencia de tal riesgo quede demostrada por los poderes públicos. Las normas relativas a la aplicación de ese criterio suplementario se establecen en el anexo I, parte $\mathrm{B}^{\mathrm{r}}$.

2. Si, por lo que respecta a la concesión de autorizaciones para nuevas plantaciones, los Estados miembros deciden aplicar uno o varios de los criterios de admisibilidad contemplados en el artículo 64, apartado I, letras a) a c), del Reglamento (UE)

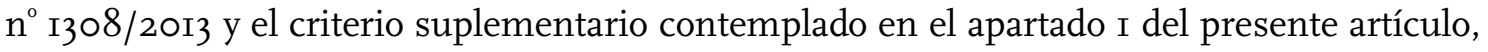
podrán aplicar esos criterios a nivel nacional o a un nivel territorial inferior.

3. Si los Estados miembros aplican uno o varios de los criterios de prioridad contemplados en el artículo 64, apartado 2, del Reglamento (UE) n 1308/2013, se aplicarán las normas establecidas en el anexo II, partes $\mathrm{A}$ a $\mathrm{H}^{\mathrm{r}}$, del presente Reglamento. Los Estados

\footnotetext{
${ }^{16}$ Anexo I: Normas relativas al criterio de admisibilidad previsto en el artículo 64, apartado I, letra c), del Reglamento (UE) $n^{\circ}$ I308/20I3 y al criterio suplementario contemplado en el artículo 2, apartado I, del presente Reglamento: A. Criterio contemplado en el artículo 64, apartado I, letra c), del Reglamento (UE) n ${ }^{\circ}$ 308/20I3 El criterio contemplado en el artículo 64, apartado I, letra c), del Reglamento (UE) n ${ }^{\circ}$ I308/20I3 se considerará cumplido si se reúne alguna de las condiciones siguientes: I) la superficie o superficies para nuevas plantaciones se destinan a la producción de vinos con una denominación de origen protegida específica de la zona de que se trate, o 2) si la superficie o superficies para nuevas plantaciones no se destinan a la producción de vinos con una denominación de origen protegida específica de la zona de que se trate, el solicitante se comprometerá a: a) no utilizar ni comercializar las uvas producidas en esas nuevas plantaciones para producir vinos con denominación de origen protegida, si esas superficies están situadas en zonas que puedan optar a tal producción, b) no arrancar y replantar vides con la intención de hacer que la superficie replantada pueda optar a la producción de vinos con la denominación de origen protegida específica. Los solicitantes se comprometerán a lo especificado en el punto 2 del párrafo primero durante un período de tiempo limitado que fijará el Estado miembro y que no podrá ir más allá del 3I de diciembre de 2030.
}

${ }^{17}$ B. Criterio suplementario contemplado en el artículo 2, apartado I, del presente Reglamento El criterio suplementario contemplado en el artículo 2, apartado I, del presente Reglamento se considerará cumplido si se reúne alguna de las condiciones siguientes: I) la superficie o superficies para nuevas plantaciones se destinan a la producción de vinos con la indicación geográfica protegida específica de la zona de que se trate, o 2) si la superficie o superficies para nuevas plantaciones no se destinan a la producción de vinos con la indicación geográfica protegida específica de la zona de que se trate, el solicitante se comprometerá a: a) no utilizar ni comercializar las uvas producidas en esas nuevas plantaciones para producir vinos con indicación geográfica protegida, si esas superficies están situadas en zonas que puedan optar a tal producción; b) no arrancar y replantar vides con la intención de hacer que la superficie replantada pueda optar a la producción de vinos con la indicación geográfica protegida específica. Los solicitantes se comprometerán a lo especificado en el punto 2 del párrafo primero durante un período de tiempo limitado que fijará el Estado miembro y que no podrá ir más allá del 3I de diciembre de 2030 .

${ }^{18}$ ANEXO II Normas relativas a los criterios de prioridad enumerados en el artículo 64, apartado 2, letras a) a h), del Reglamento (UE) $\mathrm{n}^{\circ} \mathrm{I308/2013}$ y a los criterios suplementarios contemplados en el artículo 2, apartado 3, del presente Reglamento A. Criterio contemplado en el artículo 64, apartado 2, letra a), del

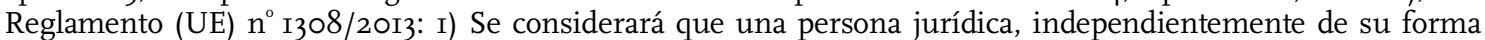
jurídica, cumple este criterio si reúne alguna de las siguientes condiciones: a) una persona física que está plantando vides por primera vez y está establecida en calidad de jefe de explotación («nuevo viticultor») ejerce un control efectivo y a largo plazo sobre la persona jurídica, en cuanto a las decisiones relativas a la gestión, los beneficios y los riesgos financieros; cuando varias personas físicas, incluidas las personas que no sean nuevos viticultores, participen en el capital o la gestión de la persona jurídica, el nuevo viticultor estará en condiciones de ejercer ese control efectivo y a largo plazo por sí solo o conjuntamente con otras personas, o b) cuando una 
persona jurídica sea individual o conjuntamente controlada por otra persona jurídica, las condiciones establecidas en la letra a) se aplicarán a cualquier persona física que ejerza el control de esa otra persona jurídica. Las condiciones establecidas en las letras a) y b) del párrafo primero serán aplicables, mutatis mutandis, al grupo de personas físicas, independientemente del estatuto jurídico que conceda la legislación nacional a ese grupo y a sus miembros. 2) Los Estados miembros podrán decidir imponer la condición suplementaria de que el solicitante sea una persona física que, en el año de la presentación de la solicitud, no tenga más de 40 años («joven productor»). Se considerará que las personas jurídicas a que se refiere el punto I cumplen la condición suplementaria mencionada en el párrafo primero del presente punto si la persona física a que se refiere el punto I, párrafo primero, letras a) y b), no tiene más de 40 años en el año en que se presente la solicitud. Las condiciones previstas en el párrafo segundo se aplicarán, mutatis mutandis, al grupo de personas físicas a que se refiere el punto I, párrafo segundo. 3) Los Estados miembros podrán exigir a los solicitantes que, durante un período de cinco años, se comprometan a no vender ni arrendar la nueva o nuevas plantaciones a otra persona física o jurídica. Si el solicitante es una persona jurídica o un grupo de personas físicas, los Estados miembros podrán solicitar también al solicitante que, durante un período de cinco años, se comprometa a no transferir a otra persona o a otras personas el ejercicio del control efectivo y a largo plazo de la explotación, en cuanto a las decisiones relativas a la gestión, los beneficios y los riesgos financieros, a no ser que esa persona o personas reúnan las condiciones de los puntos I y 2 que eran de aplicación en el momento de la concesión de las autorizaciones. B. Criterio contemplado en el artículo 64, apartado 2, letra b), del Reglamento (UE) $\mathrm{n}^{\circ} \mathrm{I308/2013}$ El criterio contemplado en el artículo 64, apartado 2, letra b), del Reglamento (UE) n 1308/2013 se considerará cumplido si se reúne alguna de las condiciones siguientes: I) El solicitante se compromete a cumplir, durante un período mínimo de entre cinco y siete años, las disposiciones sobre producción ecológica previstas en el Reglamento (CE) n 834/2007 del Consejo, de 28 de junio de 2007 , sobre producción y etiquetado de los productos ecológicos y por el que se deroga el Reglamento (CEE) n²092/9I (DO L i89 de 20.7.2007, p. I) y, si procede, las del Reglamento (CE) $\mathrm{n}^{\circ} 889 / 2008$ de la Comisión, Reglamento (CE) $n^{\circ} 889 / 2008$ de la Comisión, de 5 de septiembre de 2008 , por el que se establecen disposiciones de aplicación del Reglamento (CE) n $n^{\circ}$ 34/2007 del Consejo, sobre producción y etiquetado de los productos ecológicos, con respecto a la producción ecológica, su etiquetado y su control (DO L 250 de I8.9.2008, p. I) en la superficie o superficies para nueva plantación o en toda la explotación agrícola. Ese período no podrá ir más allá del 3I de diciembre de 2030. Los Estados miembros podrán considerar cumplido el criterio si los solicitantes ya son viticultores (Según la definición del artículo 2, letra a), del Reglamento (CE) n 436/2009 de la Comisión, de 26 de mayo de 2009, por el que se establecen disposiciones de aplicación del Reglamento (CE) $n^{\circ}$ 479/2008 del Consejo en lo que respecta al registro vitícola, a las declaraciones obligatorias y a la recopilación de información para el seguimiento del mercado, a los documentos que acompañan al transporte de productos y a los registros que se han de llevar en el sector vitivinícola (DO L I28 de 27.5.2009, p. I5) en el momento de la presentación de la solicitud y han estado aplicando efectivamente las disposiciones sobre producción ecológica a que se refiere el párrafo primero en toda la superficie plantada de vid de la explotación correspondiente durante al menos los cinco años anteriores a la presentación de la solicitud. 2) El solicitante se compromete a cumplir alguna de las siguientes directrices o regímenes de certificación más estrictos que las normas obligatorias pertinentes establecidas con arreglo al título VI, capítulo I, del Reglamento (UE) n ${ }^{\circ}$ 1306/20I3 durante un período mínimo de entre cinco a siete años que, en cualquier caso, no se prolongará más allá del 3I de diciembre de 2030: a) directrices específicas por cultivos o sectores para la gestión integrada de plagas que sean adecuadas para la viticultura, de acuerdo con el artículo I4, apartado 5, de la Directiva 2009/128/CE del Parlamento Europeo y del Consejo, de 2I de octubre de 2009 , por la que se establece el marco de la actuación comunitaria para conseguir un uso sostenible de los plaguicidas (DO L 309 de 24.II.2009, p. 7I), de existir tales directrices; b) regímenes nacionales de certificación para la producción integrada que sean adecuados para la viticultura; c) regímenes nacionales o regionales de certificación de la conformidad con la legislación ambiental en relación con la calidad del agua y/o del suelo, la biodiversidad, la preservación del paisaje, la mitigación del cambio climático y/o la adaptación a ese fenómeno, y que sean pertinentes para la viticultura. Los regímenes de certificación mencionados en las letras b) y c) del párrafo primero certificarán que el agricultor aplica en su explotación prácticas conformes con las normas nacionales de producción integrada o con los objetivos indicados en la letra c) del párrafo primero. Esa certificación correrá a cargo de organismos de certificación acreditados de acuerdo con el capítulo II del Reglamento (CE) n $n^{\circ} 65 / 2008$ del Parlamento Europeo y del Consejo Reglamento (CE) no 765/2008 del Parlamento Europeo y del Consejo, de 9 de julio de 2008, por el que se establecen los requisitos de acreditación y vigilancia del mercado relativos a la comercialización de los productos y por el que se deroga el Reglamento (CEE) no 339/93 (DO L 2I8 de i3.8.2008, p. 30) y conformes con las normas armonizadas pertinentes («Evaluación de la conformidad. Requisitos para organismos que certifican productos, procesos y servicios» o «Evaluación de la conformidad. Requisitos para los organismos que realizan la auditoría y la certificación de sistemas de gestión»). Los Estados miembros podrán considerar cumplido el criterio cuando los solicitantes ya sean viticultores en el momento de la presentación de la solicitud y hayan estado aplicando efectivamente las directrices o regímenes de certificación a que se refiere el párrafo primero en toda la superficie plantada de vid de la explotación correspondiente durante al menos los cinco años anteriores a la presentación de la solicitud. 3) En caso de que en el programa o programas de desarrollo rural de los Estados miembros se incluya una o varias operaciones específicas del tipo «agroambiente y clima» establecidas en el artículo 28 del Reglamento (UE) no I305/2013 del Parlamento Europeo y del Consejo, de I7 de diciembre de 20I3, relativo a la ayuda al desarrollo rural a través del Fondo Europeo Agrícola de Desarrollo Rural (Feader) y por el que se deroga el Reglamento (CE) no I698/2005 del Consejo (DO L 347 de 20.I2.2013, p. 487) que puedan aplicarse a zonas plantadas de vid que sean pertinentes para la superficie específica indicada en la solicitud, y siempre que se 
disponga de los fondos suficientes, el solicitante es admisible para ese tipo de operación o operaciones y se compromete a solicitarlas en relación con la superficie o superficies para nuevas plantaciones a ser plantada(s) y a cumplir las obligaciones establecidas en el programa o programas de desarrollo rural correspondientes respecto a la operación o operaciones especificas del tipo «agroambiente y clima». 4) La superficie concreta indicada en esa solicitud estará situada en pendientes con terrazas. Además, los Estados miembros podrán exigir a los productores que, durante un período mínimo de entre cinco y siete años, se comprometan a no arrancar y replantar vides en superficies que no cumplan esas condiciones. Ese período no podrá ir más allá del 3I de diciembre de 2030. C. Criterio contemplado en el artículo 64, apartado 2, letra c), del Reglamento (UE) $\mathrm{n}^{\circ}$ I308/20I3 El criterio contemplado en el artículo 64, apartado 2, letra c), del Reglamento (UE) n $\mathrm{I}_{308 / 2013} \mathrm{se}$ considerará cumplido si se reúnen todas las condiciones siguientes: I) la superficie o superficies específicas indicadas en la solicitud pasaron a ser propiedad del solicitante como consecuencia del intercambio con otra $u$ otras superficies plantadas de vid en el marco de un proyecto de concentración parcelaria; 2) la superficie o superficies indicadas en la solicitud no están plantadas de vid o están plantadas de vid en una superficie inferior a la de la superficie o superficies perdidas como consecuencia de la ejecución de ese proyecto de concentración parcelaria; 3) la superficie total objeto de la solicitud de autorización no excede de la diferencia (de haberla) entre el área plantada de vid en la superficie o superficies que antes eran de su propiedad y la indicada en la solicitud. D. Criterio contemplado en el artículo 64, apartado 2, letra d), del Reglamento (UE) n 1308/2013 El criterio contemplado en el artículo 64, apartado 2, letra d), del Reglamento (UE) n⿳ 1308/2013 se considerará cumplido si la superficie o superficies especificas indicadas en la solicitud están situadas en alguno de los tipos de zonas siguientes: I) zonas afectadas por la sequedad, con una relación entre las precipitaciones anuales y la evapotranspiración potencial anual inferior al 0,$5 ; 2$ ) zonas con una profundidad de enraizamiento superficial inferior a $30 \mathrm{~cm}$; 3) zonas con suelos de una textura y pedregosidad desfavorables, de acuerdo con la definición y los umbrales establecidos en el anexo III del Reglamento (UE) $\mathrm{n}^{\circ} \mathrm{I305/2013}$; 4) zonas con pendientes pronunciadas de más del I5 \% como mínimo; 5) zonas situadas en áreas de montaña de al menos $500 \mathrm{~m}$ de altitud, con exclusión de los altiplanos; 6) zonas situadas en las regiones ultraperiféricas de la Unión a que se refiere el artículo 349 del TFUE y en las islas menores del mar Egeo, según la definición del Reglamento (UE) $\mathrm{n}^{\circ}$ 229/2013 del Parlamento Europeo y del Consejo, de 13 de marzo de 2013, por el que se establecen medidas específicas en el sector agrícola en favor de las islas menores del mar Egeo y por el que se deroga el Reglamento (CE) $n^{\circ}$ I405/2006 del Consejo (DO L 78 de 20.3.20I3, p. 4I), o en pequeñas islas que tengan una superficie total que no exceda de $250 \mathrm{~km}^{2}$ y estén caracterizadas por limitaciones estructurales o socioeconómicas. Además, los Estados miembros podrán exigir a los productores que, durante un período mínimo de entre cinco y siete años, se comprometan a no arrancar y replantar vides en zonas que no se enfrenten a limitaciones naturales o a otras limitaciones específicas. Ese período no podrá ir más allá del 3I de diciembre de 2030. Como mucho hasta 20I8, los Estados miembros podrán decidir excluir a una o varias de las zonas contempladas en el párrafo primero del cumplimiento de este criterio de prioridad si no están en condiciones de evaluar con efectividad su conformidad. E. Criterio contemplado en el artículo 64, apartado 2, letra e), del Reglamento (UE) $\mathrm{n}^{\circ} \mathrm{I} 308 / 20 \mathrm{I3}$ El criterio contemplado en el artículo 64, apartado 2, letra e), del Reglamento (UE) n ${ }^{\circ}$ I308/20I3 se considerará cumplido si la sostenibilidad económica del proyecto correspondiente ha quedado establecida sobre la base de uno o varios de las siguientes metodologías de análisis financiero de proyectos de inversión agraria: I) Valor actual neto (VAN), 2) Tasa interna de rentabilidad (TIR), 3) Relación costes-beneficios (C/B) 4) Período de amortización (PA) 5) Beneficio neto incremental (BNI) La metodología se aplicará de una manera que resulte adaptada al tipo de solicitante. Los Estados miembros exigirán además al solicitante que realice la nueva plantación de vides de acuerdo con las características técnicas indicadas en la solicitud. F. Criterio contemplado en el artículo 64, apartado 2, letra f), del Reglamento (UE) n ${ }^{\circ}$ 1308/20I3 El criterio contemplado en el artículo 64, apartado 2, letra f), del Reglamento (UE) n ${ }^{\circ}$ 1308/20I3 se considerará cumplido si el potencial de aumento de la competitividad ha quedado establecido sobre la base de alguna de las consideraciones siguientes: I) las superficies para nueva plantación de un viticultor existente pueden generar economías de escala gracias a una reducción notable de los costes unitarios específicos de la nueva plantación en relación con la media de los viñedos existentes en la explotación o con la situación media de la región; 2) las superficies para nueva plantación de un viticultor existente pueden generar una mayor adaptación a la demanda del mercado gracias a un aumento de los precios del producto o de las salidas comerciales en relación con los viñedos existentes en la explotación o con la situación media de la región; 3) las superficies para nueva plantación de un nuevo viticultor pueden propiciar un modelo de producción agrícola más rentable que la media de la región. Los Estados miembros podrán detallar más en profundidad las consideraciones enumeradas en los puntos I, 2 y 3 del párrafo primero. Los Estados miembros exigirán además al solicitante que realice la nueva plantación de vides de acuerdo con las características técnicas indicadas en la solicitud. G. Criterio contemplado en el artículo 64, apartado 2, letra g), del Reglamento (UE) n 1308/2013 El criterio contemplado en el artículo 64, apartado 2, letra g), del Reglamento (UE) $n^{\circ}$ I308/2013 se considerará cumplido si la superficie o superficies que van a plantarse están situadas en la zona geográfica de producción de una denominación de origen protegida o una indicación geográfica protegida existentes, si las uvas que van a producirse se destinan a la producción de vinos con una denominación de origen protegida o una indicación geográfica protegida, y si se cumple alguna de las condiciones siguientes: I) la superficie o superficies que van a plantarse tienen mejores características edafoclimáticas en comparación con la media de otras superficies plantadas con viñedos conformes con el pliego de condiciones de la indicación geográfica de la misma región; 2) la variedad o variedades de uva o los clones correspondientes que van a plantarse están mejor adaptados a las características edafoclimáticas específicas de la superficie o superficies donde van a establecerse las plantaciones en comparación con superficies con viñedos conformes con el pliego de condiciones de la indicación geográfica, con las mismas características 
miembros podrán aplicar asimismo los criterios objetivos y no discriminatorios suplementarios del comportamiento previo del productor y de las organizaciones sin ánimo de lucro con finalidad social que hayan recibido tierras decomisadas en casos de terrorismo y delitos de otro tipo. Las normas relativas a la aplicación de esos criterios suplementarios se establecen en el anexo II, parte I.

4. Si, por lo que respecta a la concesión de autorizaciones para nuevas plantaciones, los Estados miembros deciden aplicar uno o varios de los criterios de prioridad contemplados en el artículo 64, apartado 2, letras a) a h), del Reglamento (UE)

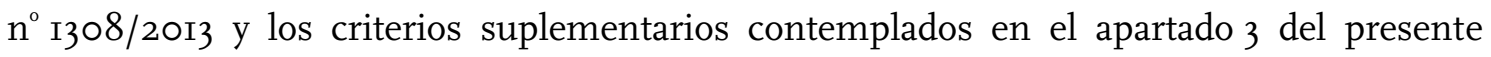
artículo, podrán aplicar dichos criterios de manera uniforme a escala nacional o con diversos grados de importancia en las diferentes zonas de los Estados miembros.

edafoclimáticas y situadas en la misma región, pero plantadas con otras variedades o con otros clones de la misma variedad o variedades; 3) la variedad o variedades de uva o los clones correspondientes que van a plantarse contribuyen a aumentar la diversidad de las variedades de uva o de los clones de variedades existentes en la misma zona geográfica de producción de la denominación de origen protegida o de la indicación geográfica protegida; 4) el sistema o sistemas de formación de la vid que van a utilizarse o la estructura de los viñedos que va a establecerse en las superficies de nueva plantación tienen el potencial de producir uvas de mejor calidad que en el caso de los sistemas de formación y/o las estructuras que predominan en la misma zona geográfica de producción de la denominación de origen protegida o de la indicación geográfica protegida. Los Estados miembros podrán detallar más en profundidad las condiciones enumeradas en los puntos I a 4 del párrafo primero. Los Estados miembros exigirán además al solicitante que plante las vides de acuerdo con las características técnicas indicadas en la solicitud. Los Estados miembros podrán aplicar este criterio de prioridad a las solicitudes relativas a nuevas plantaciones en una zona delimitada en el expediente técnico adjunto a la solicitud para proteger una denominación de origen o una indicación geográfica que está sometida al procedimiento nacional preliminar o al período de examen de la Comisión. En tal caso, las condiciones indicadas en los puntos I a 4 del párrafo primero se aplicarán mutatis mutandis. H. Criterio contemplado en el artículo 64, apartado 2, letra h), del Reglamento (UE) n ${ }^{\circ}$ 1308/20I3 El criterio contemplado en el artículo 64, apartado 2, letra h), del Reglamento (UE) n ${ }^{\circ}$ 1308/20I3 se considerará cumplido si el tamaño de la explotación del solicitante en el momento de la presentación de la solicitud se ajusta a los umbrales establecidos por los Estados miembros a nivel nacional o regional sobre la base de criterios objetivos. Esos umbrales serán los siguientes: I) 0,5 hectáreas como mínimo en el caso de explotaciones pequeñas; 2) 50 hectáreas como máximo en el caso de explotaciones medianas. Los Estados miembros podrán exigir, además, que se cumpla una o varias de las condiciones siguientes: i) que aumente el tamaño de la explotación del solicitante como consecuencia de la nueva plantación; 2) que el solicitante disponga de una superficie ya plantada con viñedos que no esté acogida a las exenciones previstas en el artículo 62, apartado 4, del Reglamento (UE) n ${ }^{\circ}$ 1308/20I3 en el momento de la presentación de la solicitud. Deberán comunicarse a la Comisión los umbrales indicados en los puntos I y 2 del párrafo primero. I. Criterios suplementarios contemplados en el artículo 2, apartado 3, del presente Reglamento I. Comportamiento previo del productor. El criterio suplementario contemplado en el artículo 2, apartado 3, del presente Reglamento se considerará cumplido si el solicitante no ha plantado vides sin autorización como se indica en el artículo 7I del Reglamento (UE) n I308/2013, o sin derecho de plantación como se menciona en los artículos 85 bis y 85 ter del Reglamento (CE) $n^{\circ}$ I234/2007. Los Estados miembros podrán exigir, además, que se cumpla una o varias de las condiciones siguientes: i) que no haya vencido ninguna autorización concedida anteriormente al solicitante con arreglo al artículo 64 del Reglamento (UE) $\mathrm{n}^{\circ}$ I308/2013 por no haber sido utilizada; 2) que el solicitante no haya incumplido ninguno de los compromisos indicados en las partes A y B del anexo I, en las partes A, B, D, E, F y G del presente anexo y en el punto II de la presente parte; 3) que el solicitante no tenga plantadas con vides superficies que hayan dejado de producir desde hace al menos ocho años. II. Organizaciones sin ánimo de lucro con finalidad social que hayan recibido tierras decomisadas en caso de terrorismo y delitos de otro tipo. El criterio suplementario contemplado en el artículo 2 , apartado 3, del presente Reglamento se considerará cumplido si el solicitante es una persona jurídica, con independencia de su forma jurídica, y se reúnen las condiciones siguientes: i) que el solicitante sea una organización sin ánimo de lucro cuya actividad tenga únicamente una finalidad social; 2) que el solicitante utilice la tierra decomisada únicamente con fines sociales, como establece el artículo Io de la Directiva 20I4/42/UE del Parlamento Europeo y del Consejo, de 3 de abril de 20I4, sobre el embargo y el decomiso de los instrumentos y del producto del delito en la Unión Europea (DO L I27 de 29.4.2014, p. 39). Los Estados miembros podrán exigir también a los solicitantes que cumplan este criterio que, durante un período que deberá determinar el Estado miembro, se comprometan a no vender ni arrendar la nueva o nuevas plantaciones a otra persona física o jurídica. Ese período no podrá ir más allá del 3I de diciembre de 2030. 
5. El uso de uno o varios de los criterios enumerados en el artículo 64, apartado 2, del Reglamento (UE) n ${ }^{\circ}$ I308/2013 como criterios de admisibilidad a uno de los niveles geográficos mencionados en el artículo 63 , apartado 2 , se considerará debidamente justificado a efectos del artículo 64, apartado I, letra d), si tiene por objeto resolver un problema específico del sector vitícola a ese nivel geográfico específico que solo puede solucionarse mediante tal restricción.

6. Sin perjuicio de las normas establecidas en los anexos I y II en lo que se refiere a los criterios de admisibilidad y de prioridad específicos, los Estados miembros adoptarán medidas adicionales, cuando sea necesario, a fin de evitar que los solicitantes de autorizaciones eludan los criterios de admisibilidad y de prioridad incluidos en esos anexos».

Teniendo en cuenta el artículo iı8 del Reglamento (UE) n I306/20I3 y para abordar las diferencias naturales y socioeconómicas y las distintas estrategias de crecimiento de los agentes económicos en las diversas zonas de un territorio dado, debe permitirse a los Estados miembros que apliquen los criterios de admisibilidad y de prioridad a que se refiere el artículo 64, apartados I y 2, del Reglamento (UE) n ${ }^{\circ}$ 1308/2013, así como los nuevos criterios de admisibilidad y de prioridad introducidos por el presente Reglamento, de forma diferente a nivel regional, o según se trate de zonas específicas que puedan optar a una denominación de origen protegida, o de zonas específicas que puedan optar a una indicación geográfica protegida o de zonas sin indicación geográfica. Tales diferencias en la aplicación de esos criterios en las diversas zonas de un territorio concreto deben basarse siempre en las diferencias entre esas zonas.

Para dar respuesta a los casos de elusión no previstos por el presente acto, los Estados miembros deben adoptar medidas para evitar la elusión de los criterios de admisibilidad y de prioridad por los solicitantes de autorizaciones cuando sus acciones no estén cubiertas por las disposiciones antielusión establecidas en el presente Reglamento en relación con los criterios específicos de admisibilidad y de prioridad.

\section{II.3. Replantaciones ${ }^{19}$}

La cuestión se regula en el artículo 66 del Reglamento I308/2013, el cual dispone lo siguiente:

«I. Los Estados miembros concederán de forma automática una autorización a los productores que hayan arrancado una superficie de vides a partir del I de enero de $2016 \mathrm{y}$ hayan presentado una solicitud. Dicha autorización corresponderá al equivalente de esa superficie en cultivo puro. Las superficies cubiertas por dicha autorización no serán contadas a efectos del artículo 63.

2. Los Estados miembros pueden conceder la autorización contemplada en el apartado i a los productores comprometidos a arrancar una superficie de vides si el

\footnotetext{
19 Sobre las replantaciones véase SÁNCHEZ HeRnÁNDEZ, A, «El arrendamiento rústico para plantar y aprovechar viñas y los derechos de viñedo», en El régimen jurídico del viñedo y tráfico jurídico privado: actas de las VI Jornadas de Derecho Agrario, Logroño, I4, I5 y I6 de mayo de 200I, 2002, págs. 7I-IO० y DE PABLo CoNTRERAS (Dir.), El régimen jurídico de las plantaciones y replantaciones de viñedo. (Derecho comunitario, estatal y de la Comunidad Autónoma de La Rioja), Logroño, Ed. Gobierno y Universidad de La Rioja, 2002, págs. 279-330.
} 
arranque de la superficie se lleva a cabo, como muy tarde, al término de la cuarta campaña siguiente a la plantación de las nuevas vides.

3. La autorización contemplada en el apartado I será utilizada en la misma explotación donde se realizó el arranque. En las superficies que puedan optar a la producción de vinos con denominaciones de origen protegidas e indicaciones geográficas protegidas, los Estados miembros podrán restringir, basándose en una recomendación de una organización profesional, de conformidad con el artículo 63, la replantación de vides que cumplan con la misma denominación de origen protegida o especificación de indicación geográfica que la superficie arrancada.

4. El presente artículo no se aplicará en el caso de arranque de plantaciones no autorizadas».

El artículo 66, apartado 2, del Reglamento (UE) n I308/2013 prevé la posibilidad de coexistencia de vides a cuyo arranque se haya comprometido el productor con vides nuevamente plantadas. Se explica por el legislador que para evitar irregularidades, los Estados miembros deben tener la posibilidad de garantizar por los medios adecuados que se respete el compromiso de arranque, incluido el requisito de constituir una garantía que acompaña a la concesión de una autorización de replantación anticipada. Además, es necesario precisar que, en caso de que el arranque no se realice dentro del plazo de cuatro años establecido por esa disposición, las vides plantadas en la superficie en cuestión deben considerarse no autorizadas ${ }^{20}$.

El artículo 66, apartado 3, del Reglamento (UE) n ${ }^{\circ}$ 1308/2013 permite a los Estados miembros limitar la replantación en las superficies que puedan optar a la producción de vinos con denominaciones de origen protegidas e indicaciones geográficas protegidas, sobre la base de una recomendación de organizaciones profesionales reconocidas y representativas. Deben definirse los motivos o razones de tales decisiones de restricción a fin de aclarar los límites de su ámbito de aplicación, garantizando al mismo tiempo la coherencia del régimen y evitando su elusión ${ }^{2 \mathrm{I}}$.

Se apunta también que es preciso garantizar, en particular, que la concesión automática de autorizaciones de replantación establecida en el artículo 66, apartado I, del

\footnotetext{
${ }^{20}$ El artículo 3 del Reglamento Delegado regula las autorizaciones para replantación anticipada, disponiendo lo siguiente: «Los Estados miembros podrán supeditar a la obligación de constituir una garantía, la concesión de una autorización a los productores comprometidos a arrancar una superficie de vides de conformidad con lo dispuesto en el artículo 66, apartado 2, del Reglamento (UE) n ${ }^{\circ}$ 1308/2013. En cualquier caso, si los productores no llevan a cabo el arranque al término del cuarto año siguiente al de la plantación de las nuevas vides, se aplicará el artículo 7I del Reglamento (UE) n I308/2013 en relación con la superficie comprometida que no haya sido arrancada».

${ }^{2 \pi}$ El artículo 4 del Reglamento Delegado regula las restricciones de replantación, disponiendo lo siguiente: «Los Estados miembros podrán restringir las replantaciones sobre la base del artículo 66, apartado 3, del Reglamento (UE) n I308/20I3, si la superficie específica de replantación está situada en una zona en la que la expedición de autorizaciones para nuevas plantaciones está limitada, de conformidad con lo dispuesto en el artículo 63, apartado 2, letra b), del Reglamento (UE) n ${ }^{\circ}$ I308/20I3, y siempre que la decisión se justifique por la necesidad de evitar un riesgo bien demostrado de devaluación significativa de una denominación de origen protegida o indicación geográfica protegida. El riesgo de devaluación significativa a que se refiere el párrafo primero no existe cuando: a) la superficie específica a replantar está situada en la misma zona de denominación de origen o indicación geográfica protegidas que la superficie arrancada, y la replantación de vides respeta el mismo pliego de condiciones de la denominación de origen o indicación geográfica protegidas que la superficie arrancada; b) la replantación está destinada a la producción de vinos sin indicación geográfica, siempre que el solicitante asuma los mismos compromisos en lo que se refiere a las nuevas plantaciones que los establecidos en el anexo I, partes A y B, punto 2, del presente Reglamento».
} 
Reglamento (UE) n ${ }^{\circ}$ I308/2013 no impide que los Estados miembros puedan limitar la emisión de autorizaciones para zonas específicas de conformidad con lo dispuesto en el artículo 63, apartado 2, letra b), y apartado 3. No obstante, debe aclararse que determinados casos específicos no pueden considerarse una elusión del régimen.

\section{II.4. Sanciones}

El artículo 64 del Reglamento (UE) n 1306/2013 prevé sanciones administrativas en caso de incumplimiento de los criterios de admisibilidad, los compromisos u otras obligaciones resultantes de la aplicación de la legislación agrícola sectorial. Para garantizar el efecto disuasorio, los Estados miembros deben poder graduar esas sanciones en función del valor comercial de los vinos producidos en los viñedos de que se trate. De conformidad con el artículo 7I, apartado 4, del Reglamento (UE) n 1308/2013, deben preverse sanciones administrativas en relación con las plantaciones no autorizadas a fin de conseguir un efecto disuasorio. El valor mínimo de esas sanciones debe corresponder a la media de la renta anual por hectárea de las superficies vitícolas a escala de la Unión, medida sobre la base del margen bruto por hectárea de superficie vitícola. Debe establecerse una graduación progresiva a partir de ese valor mínimo, en función del tiempo de incumplimiento. Los Estados miembros también deben tener la posibilidad de aplicar sanciones mínimas más elevadas a los productores de una zona determinada, cuando el valor mínimo establecido a escala de la Unión sea inferior a la media de la renta anual calculada por hectárea de la zona de que se trate. Ese aumento del valor mínimo de las sanciones debe ser proporcional a la media de la renta anual calculada por hectárea de la zona en que se sitúa la superficie vitícola no autorizada ${ }^{22}$.

\section{Protección de las Denominaciones de Origen y etiquetado}

En materia de denominaciones de origen e indicaciones geográficas y de etiquetado se ha defendido la simplificación de categorías mediante una clasificación de vinos armonizada con las normas internacionales, lo cual servirá para facilitar que los vinos con denominaciones de origen o con indicación geográfica queden mejor protegidos en terceros países $^{23}$. También en las regiones productoras de un gran volumen de vinos de mesa se

${ }^{22}$ El artículo 5 del Reglamento Delegado regula las sanciones y recuperación de costes disponiendo lo siguiente: «Los Estados miembros impondrán sanciones económicas a los productores que no cumplan la obligación establecida en el artículo 7I, apartado I, del Reglamento (UE) n 1308/2013. El importe mínimo de la sanción económica será: a) 6000 EUR por hectárea, si el productor arranca la totalidad de la plantación no autorizada en el plazo de cuatro meses a partir de la fecha de notificación de la irregularidad, de conformidad con el artículo 7I, apartado 2, del Reglamento (UE) n I308/20I3; b) I2 000 EUR por hectárea, si el productor arranca la totalidad de la plantación no autorizada durante el primer año siguiente a la expiración del período de cuatro meses; c) 20000 EUR por hectárea, si el productor arranca la totalidad de la plantación no autorizada después del primer año siguiente a la expiración del período de cuatro meses. Si se estima que los ingresos anuales obtenidos en la zona en la que se sitúan los viñedos en cuestión superan los 6 ooo EUR por hectárea, los Estados miembros podrán aumentar los importes mínimos fijados en el párrafo segundo proporcionalmente a la renta media anual por hectárea estimada para esa zona. En caso de que el Estado miembro garantice el arranque de las plantaciones no autorizadas por sus propios medios, el coste a cargo del productor de conformidad con el artículo 7I, apartado 2, del Reglamento (UE) nº I308/20I3 se calculará de manera objetiva teniendo en cuenta los costes de mano de obra, utilización de maquinaria y transporte, así como otros costes incurridos. Ese coste se añadirá a la sanción aplicable».

${ }^{23}$ Sobre las denominaciones de origen puede verse: Coello MARTín, C., Bases históricas y administrativas del derecho vitivinícola español: El sistema jurídico de las denominaciones de origen, Instituto Andaluz de Administración Pública; Coello Martín, C. y GonZÁlez Botija, F., «Reciente jurisprudencia sobre 
promueve una normalización del etiquetado en el que se mencione la variedad o la añada debidamente probadas. Esto es importante puesto que en la actualidad muchísimos consumidores se guían en sus elecciones por la añada o la variedad. Hay que tener en cuenta que la comercialización sigue siendo uno de los problemas pendientes del sector vitivinícola, junto con la difusión del consumo de vino. Se debe estudiar bien qué demanda el consumidor. Igualmente se observa que los vinos españoles de algunas regiones tienen una imagen deficiente en los mercados internacionales. Por eso en algunos casos (como el castellano-manchego) se piensa que sería bueno contar con una marca paraguas que sirva de referencia única en el nivel internacional y que las denominaciones de origen españolas se coordinasen para llevar a cabo una promoción conjunta en el mercado internacional como realizan los países del Nuevo Mundo.

Aparte de estos problemas clásicos, ya desde el plano jurídico, hay que destacar que sigue la litigiosidad en relación con las denominaciones de origen.

En primer lugar se pueden citar un par de casos relativos a la denominación de origen Lambrusco ${ }^{24}$.

Las entidades Consorzio perla tutela dei vini Reggiano e Colli di Scandiano e di Canossa y Consorzio tutela del Lambrusco di Modena entablaron un recurso de casación contra la Sentencia de 8 de noviembre de 2012 dictada por la Sala de lo ContenciosoAdministrativo (Sección Segunda) del Tribunal Superior de Justicia de Madrid en materia de marcas. La citada Sentencia estimó el recurso contencioso administrativo interpuesto contra las resoluciones de la Oficina Española de Patentes y Marcas (OEPM) de 20 de marzo de 2009 y 30 de junio de 2009, por las que se había denegado la inscripción de las marcas «Lambrusco Dell’Emilia Canottieri» y «Lambrusco Antico Casato», («Vino lambrusco dulce de la región italiana dell'Emilia»), para vinos, en la clase 33. La OEPM entendió que concurría la causa de prohibición de registro contenida en el artículo 9.I.c) de la Ley de Marcas I7/200I, de 7 de diciembre ${ }^{25}$, a la vista de que «Lambrusco es el nombre constitutivo de la Denominación de Origen controlada de este vino de Italia y que dicho nombre sólo se aplique a unos vinos que respondan plenamente a las cualidades y características regladas para ellos», no era posible acceder a la solicitud del nuevo signo. La decisión también se basó en que la marca solicitada, para vino lambrusco dulce procedente

comercialización de vinos (declaraciones saludables y uso de la misma marca comercial para identificar vinos procedentes de distintas denominaciones de origen)», Revista de derecho agrario y alimentario, $\mathrm{n}^{\circ} 29, \mathrm{n}^{\circ}$ 62, 20I3, págs. 33-58 y «Sobre el carácter declarativo del reconocimiento de una denominación de origen: el Reglamento de la denominación de origen Rueda. Comentario a la STS de 3 de octubre de 2006 (Sala de lo Contencioso- Administrativo, Sección 4. Recurso núm. 6828/2003)», Revista de administración pública, $\mathrm{n}^{\circ}$ I76, 2008, págs. 247-27I y MiLLÁN SALAS, F., «Los regímenes de calidad de los productos agrícolas y alimenticios tras el Reglamento (UE) II5I/20I2», Actualidad civil, nº IO, 2014.

${ }^{24}$ Ver SSTS de 26 de septiembre de 2014. Sección: 3. No de Recurso: 508/20I3. Ponente: Eduardo Espin Templado y de 6 de octubre de 20I4. Sección: 3. No de Recurso: iri8/2013. Ponente: Manuel Campos SanchezBordona.

${ }^{25}$ Artículo 9.I.c) de la antedicha Ley de Marcas, señala que sin la debida autorización no podrán registrarse como marcas, entre otras y en lo que ahora nos interesa, Los signos que reproduzcan, imiten o transformen creaciones protegidas por un derecho de autor o por otro derecho de propiedad industrial distinto de los contemplados en los artículos 6 y 7. La ratio de dicho precepto radica en evitar una explotación comercial no deseada por su titular de los derechos de propiedad industrial e intelectual mediante su registro como marca. Obviamente, no se denegará la inscripción de estos signos si consta la autorización de los titulares del derecho de propiedad industrial o intelectual objeto de protección. Dentro de los derechos de propiedad industrial debemos incluir, tal como entiende la resolución recurrida, así como las partes personadas, a las denominaciones de origen, por mandato del artículo I.2 del Convenio de París. 
de la región italiana Dell'Emilia mostraba una reproducción parcial de las denominaciones de origen amparadas por el Consorzio Tutela del Lambrusco di Modena y Consorzio per la tutela del Vini Reggianao e Colli di Scandiano e di Canossa «al incluir en la misma posición el elemento principal e inicial de aquellas 'LAMBRUSCO' sin estar legitimado para ello ante la evidente falta de conexión del solicitante con los productos legitimados para usar alguna de las denominaciones de origen en razón de la características de producción de los vinos amparados por ellas».

Los recurrentes mostraron su disconformidad con las resoluciones impugnadas aduciendo que la marca solicitada no se encuentra incursa en el artículo 9.I.c) de la citada Ley de Marcas por el sólo hecho de incluir en el signo el componente «LAMBRUSCO DELL'EMILIA», indicativo de la clase de vino ofertada y de su procedencia. Al respecto argumentó que LAMBRUSCO es en primer lugar un tipo de vid con 40 variedades y que, en segundo lugar, es el nombre de una serie de vinos italianos de la zona norte del país, en concreto de Emilia-Romagna. A continuación añadió que el hecho de incluir los citados vocablos en el signo solicitado, que no se reivindicaban con carácter de exclusividad, es acorde con el artículo I3 del Reglamento (CE) n 510/2006 del Consejo, de 20 de marzo de 2006 , sobre la protección de las indicaciones geográficas y de las denominaciones de origen de los productos agrícolas y alimenticios, que posibilita la utilización, como aquí acontece, del nombre de un producto agrícola o alimenticio considerado como genérico. Argumentaron que siendo el vocablo LAMBRUSCO el nombre de un tipo de vid, pretendiendo distinguir el signo solicitado vino Lambrusco dulce de la región de italiana dell'Emilia, y que además es adquirido por empresas radicadas en el norte de Italia, no podía entenderse aplicable la causa de prohibición aplicada por la OEPM, siendo veraz la información contenida en la marca solicitada. Por último entendían que no existía peligro de confusión alguna, existiendo además otras marcas con el vocablo LAMBRUSCO, sin que existiese coincidencia plena entre los vocablos utilizados en la marca solicitada y los contenidos en las denominaciones de origen opuestas. Aludían al carácter restrictivo de las normas prohibitivas.

Los Consorcios demandados mostraron su plena conformidad con las resoluciones impugnadas, entendiendo que la marca solicitada vulneraba el distintivo LAMBRUSCO objeto de las denominaciones de origen opuestas. Entendían que la no reivindicación de exclusiva en la denominación de la solicitada no amparaba la vulneración de los derechos prioritarios ajenos, ni evitaba la confusión, asociación errónea, menoscabo de la distintividad y aprovechamiento del crédito ajeno.

La Sala de instancia, por el contrario, revocó la decisión administrativa por considerar, en síntesis, que la inclusión del vocablo «Lambrusco» en la marca solicitada no supone infracción alguna a los derechos de propiedad industrial derivados de las denominaciones de origen opuestas, por lo que no concurre la causa de prohibición de registro contemplada en las resoluciones impugnadas, lo que supone una estimación del recurso origen de las presentes actuaciones. Por tanto, al dar el Tribunal de instancia la razón a los recurrentes ${ }^{26}$, los Consorcios plantearon un recurso de casación se fundaron en

\footnotetext{
${ }^{26}$ Se señala en el fallo objeto de recurso de casación que, ciertamente, la marca solicitada incluye, como elemento denominativo, el vocablo LAMBRUSCO, por lo que la cuestión litigiosa queda reducida a determinar si con dicha inclusión se infringe los derechos de propiedad industrial derivados de las denominaciones de origen opuestas. Para ello, y en primer lugar, deberá de indagarse si las mismas amparan y protegen, en exclusividad, el citado vocablo. Para dar respuesta a dicha cuestión trae a colación el artículo i9.3 Reglamento
} 
la infracción del artículo 9.I.c) de la Ley de Marcas (Ley I7/200I, de 7 de diciembre), en relación con los Reglamentos comunitarios I234/2007, de 22 de octubre, del Consejo, y 607/2009, de I4 de julio, de la Comisión. Estas entidades aducen que la sentencia impugnada ha conculcado el artículo 9.I.c) de la Ley de Marcas, al apreciar erróneamente una supuesta genericidad del vocablo «lambrusco», invocando el artículo 19.3 del Reglamento mencionado (actualmente refundido en el I234/2007, del Consejo). Afirman que el citado término está protegido por si mismo por el Anexo XV, parte B del citado Reglamento comunitario 607/2009, en relación con su artículo 62.4, protección que excluye que pueda atribuírsele la consideración de genérico. Asimismo, sostienen, el artículo II8 quaterdecies del Reglamento comunitario I234/2007 (texto consolidado; antes el

(CE) $n^{\circ} 607 / 2009$ de la Comisión de I4 de julio de 2009, por el que se establecen determinadas disposiciones de aplicación del Reglamento (CE) n $n^{\circ} 479 / 2008$ del Consejo en lo que atañe a las denominaciones de origen e indicaciones geográficas protegidas, a los términos tradicionales, al etiquetado y a la presentación de determinados productos vitivinícolas ${ }^{26}$. Dicho precepto establece que: La protección de una denominación de origen o indicación geográfica se aplicará a toda la denominación, incluidos sus elementos constitutivos, a condición de que sean distintivos en sí mismos. No se protegerán los elementos no distintivos o genéricos de una denominación de origen o indicación geográfica protegida. Como acertadamente invocan los recurrentes, el término LAMBRUSCO es característico de una concreta vid y de un concreto vino del norte de Italia, muy conocido y extendido entre los consumidores medios. Por tanto, debemos concluir en la genericidad de dicho vocablo y, por precisamente por ello, debemos negarle el carácter distintivo y relevante que al mismo le otorga la resolución impugnada en cuanto integrante de las denominaciones de origen opuestas. Prueba de la genericidad de dicho vocablo es el hecho de que las denominaciones de origen opuestas se componen, como hemos visto, de un conjunto de vocablos, no sólo del vocablo LAMBRUSCO, a través de los cuales se pretende singularizar el origen del concreto vino por ellas amparados. Se explica que es cierto, como proclama el citado artículo I9.3 del Reglamento (CE) n $n^{\circ}$ 607/2009, que la protección no sólo se extiende a toda la denominación, sino también a sus elementos constitutivos, pero ello aparece supeditado a que dichos elementos, individualmente considerados, sean en sí mismos o tenga vocación de distintividad, quedando fuera de dicha protección los elementos no distintivos o genéricos, como aquí acontece con el vocablo LAMBRUSCO. Por tanto, la inclusión de dicho vocablo en la marca solicitada no supone infracción alguna a los derechos de propiedad industrial derivados de las denominaciones de origen opuestas, por lo que no concurre la causa de prohibición de registro contemplada en las resoluciones impugnadas, lo que supone una estimación del recurso origen de las presentes actuaciones. Se observa, por otra parte, que ni la resolución impugnada, ni ninguno de los Consorcios demandados aducen o alegan la concurrencia de otras causas de prohibición absoluta, tales como las recogidas y contempladas en los artículos 5.I.c), g) o h), por lo que no se ha puesto en duda ni que el tipo de vino que se pretende amparar con la marca solicitada no sea del tipo que se dice ser: LAMBRUSCO, ni que no tenga el origen que dice tener. De cuanto antecede, no apreciándose la concurrencia de la causa de prohibición recogida en las resoluciones impugnadas, se desprende la procedencia de estimar el recurso contencioso-administrativo origen de las presentes actuaciones (fundamentos de derecho primero a cuarto). Además de la protección de las marcas y nombres comerciales inscritos, el artículo 9.I.c) de la Ley de Marcas protege otros derechos de propiedad industrial en los siguientes términos: «Artículo 9. Otros derechos anteriores. I. Sin la debida autorización, no podrán registrarse como marcas: [...] c) Los signos que reproduzcan, imiten o transformen creaciones protegidas por un derecho de autor o por otro derecho de la propiedad industrial distinto de los contemplados en los artículos 6 y 7». Ninguna de las partes niega que las denominaciones de origen de vinos (o de otros productos alimentarios) debidamente registradas constituyen derechos de propiedad industrial protegidos legalmente, lo que les proporciona la cobertura del precepto indicado. La litis se centra, por tanto, en dilucidar si la marca solicitada (Lambrusco dell'Emilia Canottieri) supone una reproducción, imitación o transformación de las denominaciones de origen representadas por los recurrentes en contra de lo que estipula el precepto invocado. Como hemos visto, así lo entendió la Oficina Española de Patentes y Marcas, que denegó el registro de dicha marca, mientras que la Sala de instancia apreció que el término coincidente (lambrusco) había devenido genérico y carecía de distintividad, por lo que procedía admitir el registro de la marca litigiosa. En efecto, la Oficina consideró que la marca solicitada significaba «una reproducción parcial de las denominaciones de origen señaladas al incluir en la misma posición el elemento principal e inicial de aquellas «Lambrusco» sin estar legitimado para ello ante la evidente falta de conexión del solicitante con los productores legitimados para usar alguna de las denominaciones de origen en razón de las características de producción de los vinos amparados por ellas. La Sentencia impugnada, por el contrario, descartó la relevancia del empleo del término «lambrusco» en igual posición que en las denominaciones de origen protegidas, por ser dicho término «característico de una concreta vid y de un concreto vino del norte de Italia, muy conocido entre los consumidores medios» y ser, en consecuencia, un término genérico y sin carácter distintivo. Además, añade la Sala, las denominaciones de origen protegidas se integran de un conjunto de vocablos, y si bien sus elementos individuales también gozan de protección, dicha protección está supeditada a que tales elementos ostenten por si mismos distintividad (art. I9.3 Reglamento CE 607/2009). 
artículo 45.3 del Reglamento 479/2008) veda que las denominaciones de origen y las indicaciones geográficas protegidas puedan pasar a ser consideradas genéricas. Niegan finalmente las entidades recurrentes que la marca tenga una finalidad informativa, ya que su reconocimiento supone ostentar un derecho al uso de la misma, mientras que la finalidad informativa se cumpliría mediante los datos incorporados en etiquetado, envoltorio y la publicidad.

Sobre la protección de los derechos de propiedad industrial por el artículo 9.I.a) de la Ley de Marcas, el Supremo considera ${ }^{27}$ que tienen razón las entidades recurrentes en

${ }^{27}$ Se consigna en este caso la doctrina jurisprudencial de la Sala de lo Contencioso-Administrativo del Tribunal Supremo, en relación con la protección jurídica de las marcas que designan productos del sector vitivinícola, amparadas en el reconocimiento de Denominaciones de Origen, con la finalidad de preservar efectivamente los derechos de los consumidores a una adecuada elección del producto ofrecido, en aras de impedir que se produzca confusión, respecto de la procedencia geográfica de un determinado producto. A tal efecto trae a colación la Sentencia de dicho Alto Tribunal de I6 de julio 20Io, rec. I894/2009, que resume dicha doctrina en los términos literales siguientes: En la sentencia de esta Sala jurisdiccional de 25 de octubre de 2002 ( $R C$ 6082/1996 ), cuya fundamentación reprodujimos en la sentencia de 5 de marzo de 2009 (RC 2784/2007), declaramos: Efectivamente, como dice la STS de 29 de enero de 1983, el espíritu y finalidad que imprime toda la materia de denominaciones de origen está presidido por la protección y garantía de la calidad específica de los vinos, impidiendo que salgan al mercado con posible engaño del consumidor, vinos protegidos por la Denominación que no sean tales. En términos análogos, la STS de igual fecha, al pronunciarse sobre la interpretación del art. I24 núm. I3 del Estatuto de la Propiedad Industrial (inmediato precedente del art. II.I.f) de la L.M ., aunque la redacción no sea idéntica) dice que tal precepto impide admitir distintivos en los que figuran leyendas que puedan constituir falsas indicaciones de procedencia de crédito $y$ de reputación industrial», pues, añade, «la firma peticionaria se aprovecharía en forma más o menos directa o involuntaria del crédito $y$ prestigio... aunque no fuesen esas sus intenciones o proyectos». La STS de 25 de mayo de 1983 dice que «incluso las marcas no prevalecen frente a la específica protección de la denominación de origen. Pero es en la STS de 29 de septiembre de I990 donde hallamos una clara doctrina sobre las denominaciones de origen. En dicha sentencia, tras definirlas (ftos. jcos. $6^{\circ}$ y $8^{\circ}$ ) se dice (en el fo f $^{\circ}{ }^{\circ} 0^{\circ}$, «in fine») que lo que garantiza la denominación de origen es que la calidad de lo producido responda de verdad a lo que espera el consumidor. Con otras palabras, trata de ganar y conservar la confianza de un consumidor que no tendrá inconveniente en pagar un precio más elevado -resultante del juego normal del mercado: a menos oferta y mayor demanda, el precio sube- si se le da lo que quiere recibir: un producto que es de una determinada calidad precisamente porque procede de una determinada comarca. Destaca esta misma sentencia (en el $\mathrm{f}^{\circ} . j^{\circ}$. $\mathrm{II}^{\circ}$ ) la conexión existente entre la defensa de los consumidores que la Constitución encomienda a todos los poderes públicos y la garantía de la veracidad de las informaciones que reciben mediante una correcta aplicación de las normas de rango inferior que regulan las Denominaciones de Origen (entre las que sin duda se incluyen las que la sentencia recurrida en casación ha inaplicado), añadiendo la STS a que ahora nos referimos (esta vez en el fo. . $^{\circ}$. $12^{\circ}$ ) $l a$ preeminencia normativa de que goza la denominación de origen, cuya eficaz protección es imprescindible en toda racional $y$ adecuada ordenación de un sector. Jurisprudencia la hasta aquí expuesta que no entra en contradicción con la STS de i8 de noviembre de I985, a la que tanta importancia atribuye la parte recurrida, y a la que debe añadirse la STS de 2 de abril de I966, de la que se desprende que sólo los productores de la denominación de origen «Manzanilla-Sanlúcar de Barrameda» pueden utilizar la denominación propia de su procedencia vinícola de calidad. A idéntica conclusión nos lleva la toma en consideración de la interpretación realizada por el T.J. (Tribunal de Justicia de las Comunidades Europeas). Dicho Tribunal, al resolver sendas cuestiones prejudiciales mediante sentencias de 9 de junio de 1998 y 28 de enero de 1999, remite al Juez Nacional la apreciación del riesgo de confusión existente cuando se utiliza como marca no la totalidad de los elementos que integran una denominación de origen compuesta sino tan solo uno de sus componentes. Apreciación que debe efectuar sobre la base de un análisis pormenorizado del contexto fáctico que le hayan expuesto las partes y empleando como parámetro de la apreciación la forma de pensar o hábitos de los consumidores, precisando que debe tomarse como preferente el tipo de consumidor medio, normalmente informado y razonablemente atento $y$ perspicaz, cuyas expectativas pueden verse defraudadas. Y en la sentencia de esta Sala jurisdiccional de 13 de marzo de 2008 (RC 3720/2005), dijimos: «Al analizar si la negativa a la inscripción de las nuevas marcas es, en este caso, conforme a derecho debemos examinar el artículo 81 del Estatuto del Vino ( $y$ las disposiciones concordantes del Reglamento de la denominación de origen «Ribera del Guadiana») en sintonía con el artículo 11.1.f) de la Ley de Marcas de 1988. El segundo de dichos preceptos, como es bien sabido, prohibe de modo absoluto el registro de los signos que puedan inducir al público a error particularmente sobre la naturaleza, la calidad, las características o la procedencia geográfica de los productos o servicios, mención esta última que es la que importa a los efectos del recurso. La razón de ser de ambas prohibiciones legales es análoga, pues, aun cuando la marca tiende a informar primordialmente sobre la procedencia empresarial del producto mientras que la denominación de origen lo hace desde la perspectiva geográfica (completada por la referencia a un determinado nivel de calidad característica de la zona), en la prohibición absoluta de registro de los signos que induzcan a error sobre la procedencia geográfica de los productos confluye el mismo designio que inspira el artículo 81 del Estatuto del Vino. En definitiva, se trata de dar prioridad a los derechos de los consumidores potencialmente inducidos a confusión respecto de la procedencia geográfica de un determinado producto amparado por el signo registrado. La aplicación conjunta de los dos preceptos mencionados no puede hacerse de un modo mecánico o automático, como si la mera inclusión -en una 
casación y estima el motivo. En primer lugar, señala que la simple aplicación del artículo 9.I.c) de nuestra Ley marcaria le lleva a la imposibilidad de admitir el registro de la marca solicitada. Como hemos visto, el precepto excluye la posibilidad de registrar marcas que «reproduzcan, imiten o transformen» derechos protegidos. Pues bien, la simple comparación entre la marca solicitada «Lambrusco dell'Emilia Canottieri» y las denominaciones de origen protegidas («Lambrusco Grasparossa di Castelvetro», «Lambrusco Salamino di S. Croce» y «Lambrusco di Sorbara») revelan con toda claridad una innegable imitación de las mismas, con la utilización en primer lugar del término más característico de dichas denominaciones («lambrusco»), seguida del nombre de una localidad o región italiana productora de vinos de uva lambrusco. Tal imitación atenta contra la protección de las citadas denominaciones de origen puesto que transmite la errónea impresión de que dicha marca pudiera constituir otra denominación de origen reconocida como tal procedente de la región Emilia-Romagna. Basta pues, aun sin entrar a considerar la valoración que pueda merecer el término «lambrusco», la constatación de que la marca solicitada se revela como una clara imitación de las denominaciones de origen

marca aspirante a su protección registral-de cualquiera de las referencias geográficas o toponímicas comprendidas en una denominación de origen (comarcas, términos municipales, localidades y pagos que componen la zona de producción) hubiera inexorablemente de ser rechazada en virtud del artículo 11.1.f) de la Ley de Marcas. Por el contrario, cuando aquella inclusión no constituya el elemento clave de la marca ni su factor identificativo más destacado y el componente geográfico o toponímico tenga, a la vez, otras acepciones relevantes o significados históricos, artísticos o conceptuales que sobrepasen la mera dimensión territorial del vocablo, en estos supuestos, decimos, será lícito acceder al registro de la marca si razonablemente se puede concluir que ésta no inducirá a error al consumidor respecto del origen geográfico del producto. No entrará en juego para tales supuestos la prohibición inserta en el citado artículo 11.1.f) de la Ley de Marcas. Debemos añadir, finalmente, que la inclusión de determinados datos o elementos geográficos inspira igualmente otras prohibiciones absolutas de registro como son las comprendidas en las letras c ) y h) del mismo artículo 11.1 de la Ley 32/1988: no cabe la inscripción de las marcas «que se compongan exclusivamente de signos o indicaciones que sirvan en el comercio para designar la especie, la calidad, la cantidad, el destino, el valor, la procedencia geográfica (...)» (letra c) ni de aquellas que «reproduzcan o imiten la denominación (...) de España, sus Comunidades Autónomas, sus municipios, provincias u otras entidades locales, a menos que medie la debida autorización» (letra h). Ninguna de ambas prohibiciones ha sido considerada en la sentencia ni tratada en el recurso de casación, que debe limitarse a examinar si concurrían las circunstancias determinantes de la aplicación del artículo 11.1 letra f) de la citada Ley 32/1988.». En suma, apreciamos que la sentencia recurrida infringe la doctrina de esta Sala del Tribunal Supremo expuesta en la sentencia de 6 de julio de 2004 (RC 1117/2001), que, en relación con la registrabilidad de aquellas marcas en cuya composición se incluyen signos indicativos de una denominación geográfica coincidente con la zona de producción y crianza de vinos delimitada por la Denominación de Origen, afirmamos: «Así las cosas es indiscutible que se conculca el artículo 11.1.f) de la Ley de Marcas, que ha sido erróneamente aplicado por la Sala de instancia. Dicho precepto prohíbe las denominaciones «que puedan inducir al público a error particularmente sobre la naturaleza, la calidad, las características o la procedencia geográfica de los productos o servicios». Y, en efecto, la marca concedida por la Oficina Española de Patentes y Marcas para vinos consiste, como hemos visto, en una denominación geográfica de una zona productora de vinos, lo que hace natural atribuir dicho origen a los vinos que ostenten semejante denominación. Esta natural y lógica asociación de que los vinos denominados Ribera del Duratón procedan de esa zona geográfica incurre en una doble infracción del citado apartado 11.f) de la Ley de Marcas. Por un lado, porque en ningún caso se ha acreditado que los vinos con esa denominación vayan a proceder efectivamente de dicha zona $y$, de no ser así, supondría llamar a engaño al consumidor que legítimamente podría esperar que dichos vinos procedieran de esa zona. $Y$, por otro lado, tiene razón la parte actora cuando denuncia la posible confusión con los vinos protegidos por la denominación de origen «Ribera de Duero», puesto que como está acreditado y reconoce la Sentencia impugnada el Duratón transcurre en gran parte por dicha zona. A este respecto es preciso rechazar las razones esgrimidas por la Sentencia de instancia para rechazar que pueda producirse esta confusión prohibida por la Ley. La afirmación de que el río Duratón no puede asociarse por cualquier persona de cultura media con la denominación Ribera de Duero, cuando el citado río Duratón es afluente del río Duero y transcurre en parte por la zona protegida por dicha denominación, no pasa de ser una afirmación apodíctica e irrazonable. Y, en segundo lugar, debe recordarse que, a la inversa de lo que se sostiene en la Sentencia, la fama o notoriedad de una marca no puede operar en sentido de atenuar la protección de la misma con el argumento de su propia recognoscibilidad por parte de los consumidores, lo que constituiría un efecto perverso de la notoriedad, sino al contrario, reforzando la protección. Y siendo comúnmente aceptada, como la propia Sentencia recoge, la notoriedad de la denominación de origen Ribera de Duero, ello debe redundar en el reforzamiento de su protección $y$, por consiguiente, en la necesidad de rechazar una marca que describe vinos que, por suscitar una evidente confusión sobre su posible procedencia de la misma zona geográfica, pudiera conducir al consumidor a la equivocada conclusión de que pertenezcan a la citada denominación de origen. A todo lo cual es preciso añadir el interés público que esta Sala ha reiterado en numerosas ocasiones en la protección de las denominaciones de origen (Sentencia de 29 de septiembre de 1.990, entre otras). 
protegidas alegadas por las entidades recurrentes para concluir que el precepto legal invocado es suficiente por sí solo para vedar la admisión de dicha marca.

Añade el Supremo que ha de resaltarse que esta apreciación sobre la marca solicitada es independiente del argumento en que se apoya la Sala de instancia respecto a que el término «lambrusco» ha devenido genérico y no distintivo, pues lo que se aprecia en la referida marca, en su integridad (término «lambrusco» seguido del nombre de una región o localidad), es que constituye una clara imitación de las denominaciones de origen protegidas, sea cual sea la valoración que se haga del citado término «lambrusco». Tal interpretación del precepto legal nacional es además conforme con lo dispuesto en el artículo iı8 quaterdecies del Reglamento (CE) I234/2007, del Consejo -versión consolidada${ }^{28}$. Pues bien, sería claramente aplicable al caso de autos la prohibición de toda imitación o evocación de la denominación de origen protegida, protección establecida en la letra b) del apartado reproducido, y que se aproxima mucho a la garantía prevista en el artículo 9.I.c) de La Ley de Marcas nacional que hemos considerado aplicable. En efecto, aunque la marca que se pretende no reproduzca las denominaciones de origen de vinos opuestas, sin duda y como hemos apreciado, constituye una «imitación o evocación» de las mismas, con una finalidad comercial, como lo es la inscripción de una marca.

A lo dicho hasta ahora se suman otras previsiones de los reglamentos comunitarios invocados por los Consorcios recurrentes, que tienen razón en las alegaciones formuladas en el motivo en relación con la imposibilidad de que el término «lambrusco» pueda ser considerado genérico y con la protección de dicho término. Como hemos visto, la Sala llega a la conclusión de que el término «lambrusco», cuyo uso habría sido determinante en la denegación de la marca por parte de la Oficina Española de Patentes y Marcas, sería genérico y carente de distintividad por referirse a un tipo de vino y uva muy conocidos; y cita en su apoyo el artículo I9.3 del Reglamento CE 607/2009, pues si bien el mismo admite la protección de los elementos constitutivos de las denominaciones, tal protección está condicionada a que dichos elementos posean carácter distintivo. Sin embargo, tal como señalan los recurrentes, entiende el Supremo que no es posible admitir semejante conclusión sobre la genericidad del citado término. En efecto, el citado Reglamento (CE) 607/2009, de la Comisión, de I4 de julio de 2009, por el que se establecen determinadas disposiciones de aplicación del Reglamento (CE) 479/2008, del Consejo, en lo que atañe a las denominaciones de origen e indicaciones geográficas protegidas, a los términos tradicionales, al etiquetado y a la presentación de determinados productos vitivinícolas Reglamento 479/2008 hoy refundido en la versión consolidada del ya citado Reglamento

\footnotetext{
${ }^{28}$ El citado artículo establece los medios de protección de las denominaciones de origen y las indicaciones de origen reconocidas, reconociendo entre ellos los siguientes: «Artículo quaterdecies Protección [...] 2. Las denominaciones de origen protegidas y las indicaciones geográficas protegidas, así como los vinos que utilicen esos nombres protegidos con arreglo al pliego de condiciones del producto, estarán protegidas de: a) todo uso comercial directo o indirecto de un nombre protegido: i) por parte de productos comparables que no se ajusten al pliego de condiciones del nombre protegido, o ii) en la medida en que ese uso aproveche la reputación de una denominación de origen o una indicación geográfica; b) toda usurpación, imitación o evocación, aunque se indique el origen verdadero del producto o el servicio o si el nombre protegido se traduce o va acompañado de los términos 'estilo', 'tipo', 'método', 'producido como', 'imitación', 'Sabor', 'parecido' u otros análogos; c) cualquier otro tipo de indicación falsa o engañosa en cuanto a la procedencia, el origen, la naturaleza o las características esenciales del producto, en el envase o en el embalaje, en la publicidad o en los documentos relativos al producto vinícola de que se trate, así como la utilización de envases que por sus características puedan crear una impresión errónea acerca de su origen; d) cualquier otra práctica que pueda inducir a error al consumidor acerca del verdadero origen del producto».
} 
(CE) I234/2007, del Consejo, del que constituye su Sección I bis-, en su artículo I9.3 establece efectivamente lo siguiente:

«Artículo 19 Protección [...] 3. La protección de una denominación de origen o indicación geográfica se aplicará a toda la denominación, incluidos sus elementos constitutivos, a condición de que sean distintivos en si mismos. No se protegerán los elementos no distintivos o genéricos de una denominación de origen o indicación geográfica protegida». Ahora bien, hay que tener en cuenta que el artículo iı8 quaterdecies ya invocado antes establece, en su apartado 3, que «las denominaciones de origen protegidas y las indicaciones geográficas protegidas no podrán pasar a ser genéricas en la Comunidad con arreglo al artículo iı8 duodecies, apartado I».

Esto es, que si bien una denominación que haya adquirido la condición de genérica ya no podrá ser protegida como denominación de origen (artículo II8 duodecies, ap.I), a la inversa, una denominación ya protegida (las afectadas en el caso lo están desde I.980) no puede ya pasar a tener la consideración de genérica por muy conocida que llegue a ser. Lo cual es una previsión plenamente lógica, pues lo contrario sería admitir un efecto perverso y perjudicial del eventual éxito de una denominación de origen protegida que llegue a ser muy conocida. Quiere esto decir que estando ya protegidas las denominaciones de origen que se oponen al reconocimiento de la marca solicitada el citado precepto hace inviable que uno de los elementos más característicos de las mismas («lambrusco») pueda recibir la consideración de término genérico como ha apreciado la Sala de instancia.

Advierte el Supremo que tienen asimismo razón los entes recurrentes cuando invocan la protección específica del uso del término «lambrusco», en cuanto denominación de un tipo de uva, fuera de las denominaciones de origen protegidas. El apartado 4 del art. 62 del ya citado Reglamento 607/2009 (precepto dedicado al nombre de la variedad de uva de vinificación) establece lo siguiente:

«Artículo 62 Nombre de la variedad de uva de vinificación [...] 4. Los nombres y sinónimos de las variedades de uva de vinificación enumerados en el anexo XV, parte B, del presente Reglamento, que contengan parte de una denominación de origen o indicación geográfica protegida y hagan referencia directamente al elemento geográfico de la denominación de origen o indicación geográfica protegida en cuestión, sólo podrán figurar en la etiqueta de una producto con denominación de origen o indicación geográfica protegida o con una indicación geográfica de un tercer país».

Pues bien, el término «lambrusco» está precisamente mencionado en la parte B de dicho Anexo XV como variedad de uva que figura como parte de varias denominaciones de origen protegidas (en concreto de cuatro, entre las que se encuentran las aducidas en el procedimiento). Es cierto que el término «lambrusco» en sí mismo no hace referencia al elemento geográfico de la denominación de origen, pues no designa una región, zona o localidad -las cuales se contienen en las denominaciones de origen protegidas, en los términos que acompañan al vocablo «lambrusco»-; «lambrusco» es, por el contrario, un término que designa un tipo de vid, de uva o de vino. Sin embargo, el citado Anexo lo incluye, sin duda por la directa vinculación de dicha uva a ciertas regiones, como término protegido, excluyendo su uso salvo en etiquetas de productos con denominación de origen o indicación geográfica protegida, o con una indicación geográfica de un tercer país (que, según el propio Anexo, sólo pueden ser Italia, Australia y Estados Unidos). 
También es interesante una reciente sentencia de 2 de junio de $2015^{29}$, donde se juzga el recurso de casación interpuesto por la representación procesal del Ayuntamiento de Querol contra la sentencia de la Sala de lo Contencioso-Administrativo (Sección $5^{a}$ ) del Tribunal Superior de Justicia de Cataluña de 24 de mayo de 20I3. Con fecha 27 de mayo de 20Io, el Ayuntamiento de Querol se dirigió al Conseller de Agricultura de la Generalitat de Catalunya, al Director General del Institut Català de la Vinya y el Vi y al Presidente del Consell Regulador de la Denominació d'Origen Penedès, presentándoles otras tantas solicitudes a fin de que el término municipal de Querol fuera incluido en la Denominación de Origen Penedès. No habiendo recibido ninguna respuesta en su debido momento, interpuso recurso contencioso-administrativo, sosteniendo que el silencio administrativo posee efecto positivo en este caso y, por tanto, que debe tenerse por estimada la solicitud de inclusión del término municipal de Querol en la Denominación de Origen Penedès. Subsidiariamente, para el supuesto de que se entendiera que el silencio administrativo tiene efecto negativo, pidió el recurrente que se declare su derecho a que el término municipal de Querol sea incluido dentro de la Denominación de Origen Penedès.

La sentencia de instancia desestima el recurso contencioso-administrativo. Niega, de entrada, que haya silencio administrativo positivo, aduciendo básicamente dos razones. La primera consiste en entender que los escritos dirigidos a las tres entidades arriba referidas no fueron verdaderas instancias o solicitudes, sino mero ejercicio del derecho de petición; y ello porque, a juicio de la Sala de instancia, no hay ninguna norma que otorgue el derecho a que un determinado territorio sea incluido en una denominación de origen. De aquí infiere que lo pedido en dichos escritos es puramente graciable y, por tanto, que se trata de ejercicio del derecho de petición. La otra razón por la que la sentencia impugnada entiende que no hay silencio positivo es que las denominaciones de origen, de conformidad con los arts. I3 y I7 de la Ley 24/2003, de la Viña y el Vino, tienen la condición de bienes de dominio público, no pudiendo ser objeto de apropiación individual, venta, enajenación o gravamen $^{30}$. A todo lo anterior añade la sentencia impugnada que la delimitación del ámbito territorial de la Denominación de Origen Penedès debe hacerse, tal como ordena la legislación autonómica, mediante orden del Conseller de Agricultura. Dicha orden, según la Sala de instancia, tiene naturaleza reglamentaria y, por tanto, está vedado a los órganos del orden jurisdiccional contencioso- administrativo declarar cómo debe quedar redactada.

Se alega en el recurso de casación infracción del art. 29 CE, así como de varios preceptos de la Ley Orgánica 4/200I, reguladora del derecho de petición. Sostiene el recurrente que la sentencia impugnada yerra al calificar sus escritos al Conseller de Agricultura de la Generalitat de Catalunya, al Director General del Institut Català de la Vinya y el Vi y al Presidente del Consell Regulador de la Denominació d'Origen Penedès como simple ejercicio del derecho de petición, ya que en ellos se reclamaba el reconocimiento de un derecho. Desde el momento en que la calificación de los escritos es errónea y no hay ejercicio del derecho de petición, concluye el recurrente que no concurre la

\footnotetext{
${ }^{29}$ Ver STS de 2 de junio de 20I5, Sección: 4 n de Recurso: 2558/2013. Ponente: Luis Maria Diez-Picazo Gimenez.

${ }^{30}$ Sobre el régimen español véase: Millán SAlAS, «La Denominación de Origen de los vinos a raíz de La Ley $24 / 2003$, de Io de julio, de la viña y el vino», Revista de derecho agrario y alimentario, $\mathrm{n}^{\circ} 20, \mathrm{~N}^{\circ} 43,2004$, pp. $5 \mathrm{I}-72$ y Serrano Suñer Hoyos y GonzÁlez Botija, Comentarios a la Ley de la viña y del vino (Ley 24/2003, de 10 de julio), Navarra, Civitas, 2004 .
} 
circunstancia que, según el art. 43 LRJ-PAC, excluye el efecto positivo del silencio administrativo.

El Supremo entiende que este motivo no puede ser acogido. Incluso admitiendo a efectos argumentativos que la calificación de dichos escritos por la sentencia impugnada no sea correcta y que, en consecuencia, se trataba de verdaderas instancias o solicitudes, no hay que olvidar que la propia sentencia impugnada da otra razón por la que el silencio administrativo no puede tener efecto positivo en este caso, a saber: que las denominaciones de origen tienen la condición de bienes de dominio público y, por consiguiente, siempre con arreglo al art. 43 LRJPAC, no cabe adquirir derechos sobre ellas mediante silencio administrativo positivo. Que la calificación de los escritos por la sentencia impugnada sea errónea resulta, así, irrelevante en lo que toca a la inexistencia de silencio administrativo positivo. Conviene señalar, para disipar cualquier posible duda, que la afirmación de la sentencia impugnada acerca de la naturaleza demanial de las denominaciones de origen es correcta. Así se establece expresamente en el ya citado art. I7 de la Ley 24/2003. Y si bien este precepto está hoy derogado, ha sido recientemente sustituido por otro de parecido tenor: el art. I2 de la Ley 6/2015.

Finalmente, se alega infracción del art.43 LRJ-PAC. Insiste el recurrente en que el silencio administrativo tiene efecto positivo en el presente caso, utilizando argumentos similares a los empleados en el motivo anterior. Niega, además, que concurra la circunstancia de adquisición de «facultades relativas al dominio público» que, con arreglo al art. 43 LRJ-PAC, excluye el silencio administrativo positivo. Pero, por las razones ya expuestas a propósito del anterior motivo, el Supremo tampoco considera que éste puede prosperar. Añade que estar incluido en una denominación de origen otorga a los correspondientes productores una especial protección. Y dada la naturaleza demanial de las denominaciones de origen, no cabe negar que la inclusión en las mismas implica la adquisición de «facultades relativas al dominio público» en el sentido del art.43 LRJ-PAC. 